\title{
Development of a Criticality Alarm System Neutron Detector:
}

\section{Final Project Report}

\author{
Austin A. ODell
}

May 1989

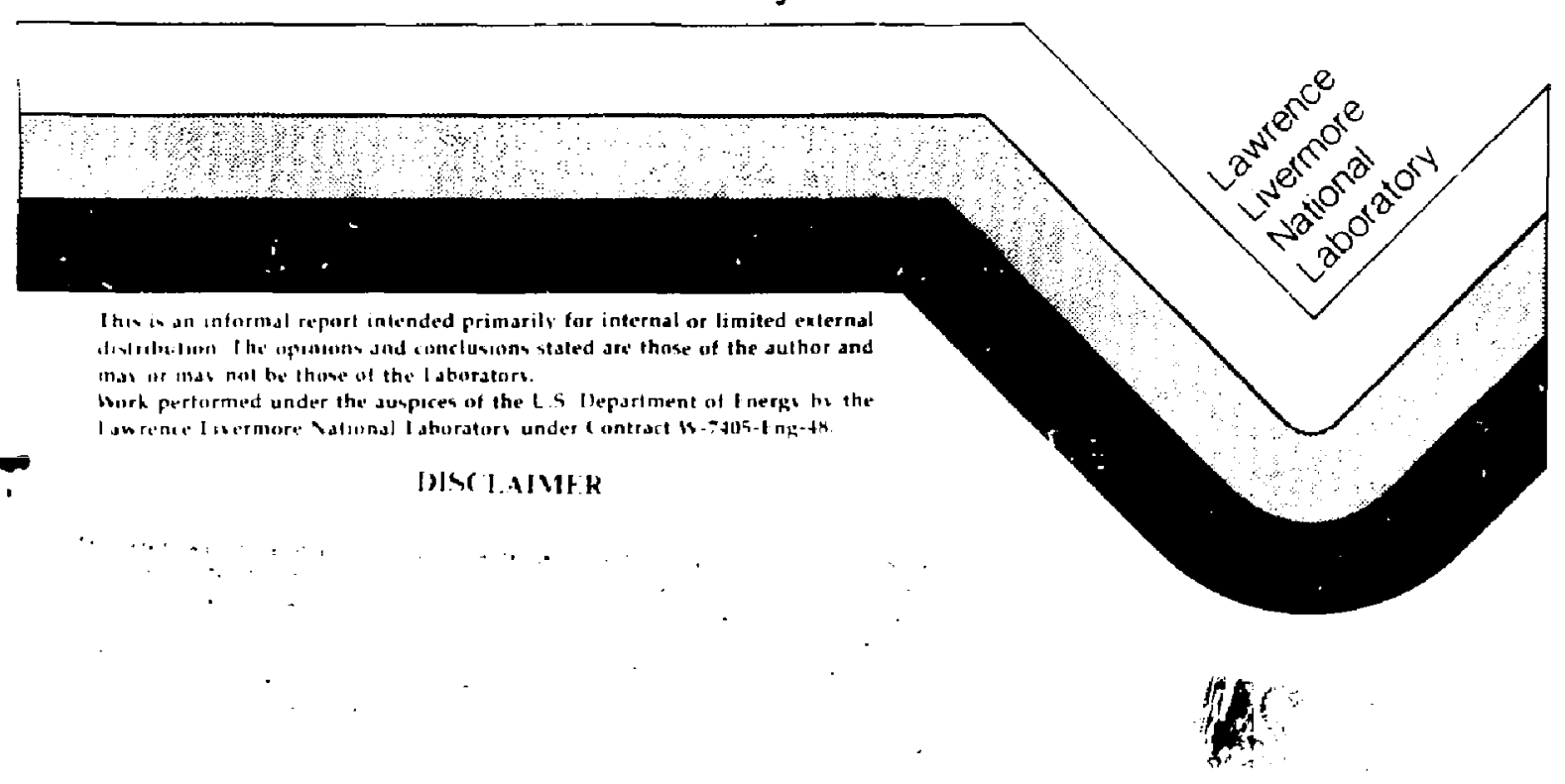




\title{
DISCL AIMER
}

This document as prepared as an account of work ponsored by an agency of the linited Stales Covernmenl Neither the United States Covernment nor the University of Californil nor any of theit employers, makes any wareasly. express or implied or asumes any legal liability or responsibility tor the accuracy, rompleteness, or usefulness of any informalion, apparatus, producl. or process disclosed, or represents that ilt uge would not infringe privately owned rights. Reference herein to any apecific cosnmercial producte, frocesh ar service by trade name, trademark. manufacturef, or atherwlse, doet not necessarily canslitule of implv its endorsemenl. recommendation, or favaring by the Uniled Stales Governmenl of the University of California. The views and opiniana of suthors expiessed herein do not necess rily glate or reflect those of the United Glates ciovernment D: the Universtti of California, and ghall nol be used for advertising or product endoesement purposes

\author{
Iha repent hat been ieptosuced \\ difertle trom in thest arailoble copt

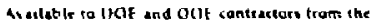

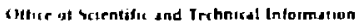

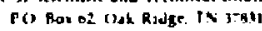

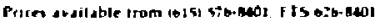 \\ Arsluple to the public tham the \\ vilional Texhnical Informsuon bervice \\ Ls Depattent at Commpice \\ gab Jot1 Roval Ru \\ Sprentirld, in rist
}

Price

Page

Code

Range

A01

Microfiche

Papercopy Prices

A02

001-750

A03

051-3no

A04

$101-200$

A05

201-300

A06

$301-400$

A07

$40:-500$

$\mathrm{A} 0 \mathrm{~B}$

$501+00$

A 09

601 


\section{Development of a Criticality Alarm System Neutron Detector:}

\section{Final Project Report}

\author{
Austin A. O'Dell, Principal Investigator
}

UCID--21361

DE89 012898

\section{Introduction}

\section{Objectives}

The primary objective of this project was to develop a prototype neutron detector for use in criticality alarm systems (CASs) at U.S. Department of Energy (DOE) and contractor facilities wherever significant amounts of fissile material are processed or stored. Constraints placed on the design of the detector were that the overall size of the detector was to be as small as practical, the input voltage requirements were to be no more than $24 \mathrm{~V}$, and that the gamma sensitivity would be as low as possible. Also, the detector should give dosimetric neutron response, and should have sufficient temporal capabilities to measure the entire range from fast ( $>1 \mathrm{~ms}$ ) to slow (seconds to minutes) excursions, and sufficient dynamic range to measure from background to over 100 times background levels to insure proper activation of the Immediatc Evacuation Alarm (IEA). Finally, the detector should insure rapid ( $<1$ s) activation of the IEA in the event of a criticality excursion.

\section{Project Overview}

This project was funded at the Lawrence Livermore National Laboratory (LLNL) by the DOE Office of Nuclear Safety (ONS), starting in FY83 and ending in FY85. Work done during these three fiscal years will be designated as Phase I, Phase II, and Phase III, respectively. A short report was submitted each quarter to our DOE/ONS sponsor, summarizing the significant activities and spending for that quarter. The activities, progress, and conclusions for each Phase are discussed in detail in this report.

Even before the start of this project, the principal investigator had visited several DOE and commercial facilities to investigate CAS installations and detectors that were in use or were currently available.

\section{Phase I Activities (FY83)}

\section{General Remarks}

Phase I activities, progress, spending, and plans were summarized in Quarterly Reports $\# 1$ and \#2.

This project started in March 1983 with additional visits to selected DOE and commercial facilities to discuss CAS detectors that were in use or were available for purchase. The facilities visited included the Savannah River Plant, the Oak Ridge Y-12 Plant, the Oak Ridge Gaseous Diffusion Plant, the Portsmouth Gaseous Diffusion and Centrifugal Scparation Facilities, the Pantex Plant, the Rocky Flats Plant, the General Electric fuel processing facilities (Wilmington, NC), and the Los Alamos National Laboratory (LANL).

To obtain a detector with a dosimetric response and high sensitivity, it quickly became apparent that we should focus on using a thermal $(0.025 \mathrm{eV})$ neutron detector surrounded by a neutron moderating 
material. Such an arrangement, using an appropriately sized moderator sphere, produces a detector with an approximate dose equivalent per fluence response over a wide range of neutron energies. Unfortunately, this type of response is not consistent with the absorbed dose values normally used in criticality safety calculations and measurements.

Once this detecter type was chosen, the main tasks for the project were to select the configuration of the moderator, to develop an effective thermal detector, to develop the special monitoring circuitry required, and to verify the detector operation by a series of electronic and irradiation tests. For the moderator, we chose a 10-in. diameter polyethylene sphere with a cylindrical hole bored to its center to accommodate the thermal neutron detectors to be studied. Polyethylene plugs were fabricated to fill the empty space bethind the detectors. A small channel was machined into each plug to accommodate the short, low-capacity coaxial cable used to connect the thermal neutron detector to the external monitoring instrumentation.

Our first detector work focused on improvements to the type of detector developed at Rocky Flats Plant (RFP) by $W$. Tyree. We hoped to obtain increased sensitivity and a broader time-response rangk', and to develop the associated electronic circuitry so that it would be compatible with the operational requirements given in the "Objectives" section above.

The RFP detector consists of a 0.5 -in. diameter silicon charged-particle detector (CPD) that detects alpha particles and tritons emitted from an external ${ }^{6} \mathrm{LiF}$ converter disk. Some fraction of the alpha particles and tritons produced by low-energy neutron interactions with the ${ }^{6} \mathrm{Li}$ in the converter escape the disk and deposil energy in the CPD. The converter disk has a hole drilled through its center to permit alpha particles from a low-activity ${ }^{230}$ Th source to impinge upon the CPD to provide a "livezero" signal for supervisory and other operational purposes. As originally designed, this detector and its associated electronic circuitry can sense detector failures or criticality excursions above a preselected threshold level, but it cannot quantitatively inonitor ambient radiation levels, nor does it yield dosimetric information.

\section{Type A Detector Development}

Our version of the RFP detector, designated as Type A, was developed in cooperation with the Eberline Instrument Corporation (EIC). The configuration of the Type A delector is shown schematically in Fig. 1. It consists of a 1-in. diameter silicon diffused-junction CPD closely coupled to a 0.75 -in. diameter by 0.032 -in. thick ${ }^{6} \mathrm{LiF}$ converter disk. The disk was supplied by Harshaw/Filtrol. Five Type A detectors were labricated for LLNL by Eberline for further test and evaluation.

LLNL participated in the development of improved and expanded versions of the monitoring electronics for this detector. Eberline subsequently incorporated the improvements into their Model DA1-7 Neutron Detector. Special efforts were made to maximize the range of the time response and to improve the temperature stability. Three monitoring chains were incorporated in this design. Two chains monitored pulse-counting rates, one low and one high. The third chain monitored the current through the detector to detect short-burst excursions. This clectronic system operated fiom a single $12 \mathrm{~V}$ dc input source and was mounted in a metal housing. The detector was connected via a short, lowcapacitance cable connected to a BNC coaxial feedthrough in the top of the housing.

\section{Type B Detector Development}

The Type B deiector (Fig. 2) resulted from our second attempt to improve the RFT detector, and was developed in cooperation with John Walter at the Tennelec Corporation. Three Type B detectors were fabricated for LLNL by Tennelec.

In this detector, a $1 . i$-in. diameter by 0.030 -in.thick ${ }^{6}$ LiF converter disk, obtained from Harshaw/Filtrol, was sandwiched between two 1-in.-diameter surface-barrier CPDs, each with a minimum sensitive thickness of 0.004-in. The entire assembly was mounted inside a special polyethylene housing, with a 2 -in. diameter and a 1.25 -in. length. Electrical connections to the CPDs were made using 0.086-in. diameter SMA semirigid coaxial cables fitted with SMA coaxial conni'ctors. Two CPDs were used to detert the alpha particles and tritons emitted from both sides of the converter 
disk, because the thickness of the disk is large compated with the range of these charged particles in 6LiF. To decrease the gamma-ray background, special attention was paid to minimizing the metallic parts. Diode-to-converter spacing was minimized to optimize charged-particle collection. The two CPD outputs were monitored independently.

\section{Type C Detector Developnient}

During a visit with technical personnel at Harshaw/Filtrol, we observed a miniature gamma-ray detector under development that used a 10-mm cubical Bismuth Germanate (BCO) scintillator mounted on a $10 \mathrm{~mm} \times 10 \mathrm{~mm}$ sensitive area Hamamatsu silicon solid-state photodiode and placed inside a thin Al light-light housing. After some discussion, we decided to develop a neutron detector using a 10-mm cubical ${ }^{6} \mathrm{Lil}(\mathrm{Eu})$ scintillator in place of the BCO. We designated this detector as Type C. Its configuration is shown schematically in Fig. 3. Harshaw/Filtrol agreed to fabricate one detector and to provide it with a miniature hybrid preamplifier, linear amplifier, and discriminator. The entire assembly was built into an Al housing with dimensions comparable to a standard preamplifier. Lineat and logic outputs, an adjustable pulse-height discriminator, and an input power jack were provided. Both the detector and the electronics operated from a single 9-12 V de power source.

For compatibility with the other detector irradiation tests performed in this project, we disconnected the detector assembly from the hybrid electronics and removed it from the Al housing. The detector was remounted in a separate thin-walled, light-tight Al housing fitted with a BNC connector. In this configuration, the detector could be connected to the same instrumentation system used for testing the Type $A$ and $B$ detectors.

A major advantage of the Type $C$ detector over the Type A or B is that the neutzons interact with ${ }^{6} \mathrm{Li}$ within the detector ilself. For each thermal neutron that interacts, the entire $4.78 \mathrm{MeV}$ interaction energy from the ${ }^{6} \mathrm{Li}(\mathrm{n}, \mathrm{t})$ alpha reaction is available to produce light in the scintillator, provided both the alpha particle and triton expend their entire kinetic energy in the crystal. In the Type A or B detectors, only one of the reaction products can be detected for each thermal neutron interaction, betausc the two particles recoil in opposite directions. Moreover, the kinetic energy of the recoil particle that is detected is generally degraded, depending upon the depth in the ${ }^{6} \mathrm{Lif}$ at which the neutron interaction occurred.

\section{Monitoring Instrumentation}

The Type $A$ detector from Eberline and the Type $\mathrm{C}$ detector from Harshaw/Filtrol were both supplied with electronics packages, while the Type B came from Tennelec without any electronics. However, except for the LANL off-site tests, irradiation testing of all detectors used a combination of LLNL-designed and high-quality commercial Nuclear Instrument Module (NIM) instrumentation in place of the electronics supplied by the manufacturers. This allowed us to compare all detectors using identical electronics.

Our project used two types of detector-monitoring systems: 1) pulse-counting using commercial preamplifiers and NIM electronics, and 2) burst-detection tircuits designad by LLNL or Eberline (for the LANL tests of the Type A detector).

Pulse-counting instrumentation (PCI) consisted of Tennelec TC171 charge-sensitive preamplificrs, Tennelex TC241 and TC243 NIM linear amplifiers, Tennelec TC250 single channsl analyzers (SCA.s), and Tennelec high-speed digital scalers. The scalers were cabled in a daisy chain to a buffered-input NIM printer, which could be operated in a manual or auto-reset/recycle mode. A Tennelec NIM ID/Date/Time-of-Day module and a Tennelec NIM timer module were also incorporated into the daisy chain to provide count-time control and unique tagging of the printed data. Sufficient preamplifiers, amplifiers, SCAs, scalers, and interconnection cables were obtained to provide eight independent channels of pulse-counting instrumentation. We designed and built an eight-channel power supply that permitted the bias voltage for each detector to be independently adjusled from 0-100 $\mathrm{V}$, with either polarity. 
The pulse-height distribution produced by any given deteclor could be measured by connecting the output of the linear amplifier for that channel to a conventional multichannel analyzer (MCA). By observing the various pulse-height distributions for electronic noise, gamma-ray interactions, and neutron interactions, the lower and upper discrimination levels of cach SCA in the PCl system w're adjusted to provide the optimum neutron signal-to-noise operation.

Adequate burst monitoring instrumentation was not developed in Phase I because of the delayed delivery of the detectors and the fixed schedule for the off-site irradiation tests at LANL. For the LANL test, Eberline offered to provide complete pulsecounting and burst monitoring instrumentation for the Type A detectors, using an Eberline digital CAS system similar to the new LLNL criticality alarm system. In addition, Eberline developed special microcomputer software for the LANL tests to measure the delay time between a fast itradiation burst and the resulting CAS alarm activation. For the Type $B$ detector, we attempted to use a burst-detection scheme suggested by Tennelec in which we monitored the de level at the "E-Out" jack of the TC171 preamp. Special circuits were built into the LLNL eightchannel bias supply chassis to deteet this voltage change. Each of the eight channels had a threshold adjustable from $0.1-8.0 \mathrm{~V}$ and a resetable latching LED indicalor. The Type C detector was developed too near the end of the Phase I work to develop a burst monitor for it.

\section{LLNL Irradiation Tests}

The Type B detectors arrived while we were packing for the off-site tests at LANL, and the Type $C$ detector had not been on hand much longer. This limiled the amount of testing we could do at LLNL before we had to go to Los Alamos. Neutron sensitivity measurements were made for one Type A detector and for the Type $\mathrm{C}$ detector. In both cases, the detector was operated inside a 10-in. diameter polyethylene spherical moderator and calibrated with a PuBe source $1 \mathrm{~m}$ away. Both the detector and the souree were positioned $1 \mathrm{~m}$ above the floor. Neutron dose-equivalent rate was calculated from the source strength. A high-sensitivity remmeter, designed at LLNL primarily for use with pulsed sources of neutrons, was also used to monitor the source output. The measured sensitivities were 14 (counts $/ \mathrm{min}) /(\mathrm{mrem} / \mathrm{hr}$ ) for the Type A detector and 635 (counts $/ \mathrm{min}) /(\mathrm{mrem} / \mathrm{hr}$ ) for the Type C detector.

In addition, pulse-height distributions were measured for the Type $A$ and $C$ detectors and are shown in Figs. 4 and 5, respectively. These measurements were also made using the moderator but with the source just $0.3 \mathrm{~m}$ from the detector. Both were $1 \mathrm{~m}$ above the floor. Note that the pulse-height distribution for the Type A detector (Fig. 4) is very broad. As indicated above, this is because most of the alpha particles and tritons lose some of their energy escaping from the external $b_{\mathrm{Lif}}$ converter.

The maximum kinetic energy given io the alpha particle when a thermal neutron interacis with ${ }^{6} \mathrm{Li}$ is $2.05 \mathrm{MeV}$, and the maximum energy for the triton is $2.73 \mathrm{MeV}$. In the Type $\mathrm{C}$ detector, these particles are both in the sensitive volume, and the total $4.78 \mathrm{MeV}$ is available to produce light. This yields the well-defined peak shown in Fig. 5 . This peak can be distorted, however, by cases where the neutron interacts near the surface of the scintillator and the alpha particle or triton escapes the sensitive volume before depositing its entire kinetic energy.

\section{LANL Off-Site Irradiation Tests}

Off-site irradiation tests were performed at the LANL Pajarito Site from 30 June-2 July 1983 using the SHEBA and CODIVA facilities. One Type C, two Type B, and three Type A detectors were irradiated at both facilitics. The LLNL pulsed-source remmeter and three Eberline DA1-6C-CC CAS gamma-ray detectors were used to monitor neuirons and gamma-rays, respectively. An Eberline digital CAS, supplied and operated by Eberline personnel, monitored the Type A and gamma-ray detectors. The Type $B$ and C detectors were monitored using the LLNL and NIM instrumentation described in the "Monitoring Instrumentation" section, above. 


\section{SHEBA}

The SHEBA critical assemily consists of a cylindrical stainless-steel tank 0.55 - $m$ diameter by 1.1 $\mathrm{m}$ high, cont uining a $5 \%$ enriched aqueous uranyl nitrate solution. This tank is centered $1.5 \mathrm{~m}$ above a concrete hoor. The uranyl-nitrate solution is transferred from a storage reservoir to the reactor tank and from the tank to the dump reservoir by a combination of air pressure and vacuum lines controlled by an arrangement of remotely operated binary valves. A critical configuration is oblained by transferring an appropriate quantity of the solution into the tank. No control rods are required to operate the assembly. The assembly can be operated in four modes: steady state, positive-period ramp, slow burst, and free evolution.

The SHEBA assembly is housed in a small low-scatter metal building near Kiva 1 at the Pajarito Site. Operation and monitoring of the assembly and monitoring of user experiments are performed at a central control room $370 \mathrm{~m}$ from the SHEBA building. Patch panets in the SHEBA building and in Kiva 1 are frovided to connect user experimental equipment to cabling that goes to the control room.

The criticality detectors and the pulsed-source remmeter were arranged in a $100^{\circ}$ arc at $2.82 \mathrm{~m}$ from the center of the SHEBA tank, $1 \mathrm{~m}$ above the floor. A telcvision camera in the SHEBA building was used to monitor the output display on the pulsed-source temmeter. The Eberline electronic packages used with the three Type A and the gamma-ray detectors were located in the SHEBA building and monitored by Eberline personnel in the control room using an Eberline Mode] DAM-4 Data Acquisition Module coupled to an Eberline Model CT-1 control terminal. Eberline also provided two microcomputers in the control room that were programmed to measure burst-to-alarm times. The two Type B detectors, requiring two data channels each, and the Type $C$ detector were connected to $\mathrm{TC} 171$ preamplifiers and the LLIJL bias supply in the SHEBA building. Preamplifier outputs were connected through the patch: panel to the $\mathrm{PCl}$ system in the control room. The run ID, date, time-of-day, count time, and counts for each of the five data channels were printed automatically for contiguous ime intervals during steadystate, exponential-ramp, and free-evolution runs.

Table 1 lists the runs performed at the SHEBA facility. Four steady-state runs $(1,2,4$, and 6$)$, four exponentially increasing power ramps $(3,5,8$, and 9), one shutdown decay run, and one freeevolution run (10) were performed. In addition, a PuBe source calibration was performed at the end of these runs. Steady-state runs were used primarily to calibrate the detectors at high rates. Long-period ramps were used to test detector linearity and saturation effects. The free-evolution run was suggested by Richard Malenfant to demonstrate the apparent runaway but eventual self-shutdown of a highly moderated system. Although interesting from a reactor physics standpoint, this run was not particularly useful for our calibrations, and in fact resulted in an unnecessarily high exposure to the detectors and electronics in the SHEBA building.

The measured sensitivities for the steady-state runs and the PuBe calibration are given in Table 2. Type A detectors are designated as A2, A4, and A6, and Type B jetectors are B1 and B2. The two charged-particle detector SCA-logic outputs for each Type B detector were summed to compute the sensitivity. An entry of "n. a." indicates no data were available. Sensitivities to the SHEBA spectrum for Type A, B, and C detectors are approximately 10,35 , and 700 (counts $/ \mathrm{min}) /(\mathrm{mrcm} / \mathrm{hr}$ ), respectively. The apparent sensitivity of the Type $C$ detector decreases at high radiation rates because of count-rate saturation. This is more clearly demonstrated in Fig, 6, which shows the response of the Type $C$ and one side of a Type B detector to the 56-s perion exponential ramp (run B). The response of the Type C detector becomes sublinear at high radiation rates and eventually saturates just before the point at which the SHEBA was sctammed. This probably reflects the fact that the electronics for this detector had not been optimized for high count rates. The lower sensitivity of the Type B detector prevented it from saturating.

\section{GODIVA}

The CODIVA IV critical assembly is an unreflected, cylindrical, metal reactor with overall dimensions of $150-\mathrm{mm}$ diameter by $150-\mathrm{mm}$ high. The center of the assembly is $2 \mathrm{~m}$ above the concretc floor. It has a total fuel mass of $66 \mathrm{~kg}$ comprised of six fuel rings made of $93.5 \%$-enriched uranium alloy that are held together by three special steel C-clamps. Three remotely inserted control rods regulate the assembly, along with a cylindrical, stainless-steel safety block. CODIVA can be operated in three modes: steady state, positive-period ramp, and fast burst. It is located in Kiva 3 at the LANL Pajarito 
Site. The assembly is remotely operated and monitored from a central control room $250 \mathrm{~m}$ away. Patch panels are provided to connect user instrumentation to existing cables between Kiva 3 and the control room.

In the GODIVA tests the detectors were arranged in a $100^{\circ}$ arc $4 \mathrm{~m}$ from the center of the assembly, $1 \mathrm{~m}$ above the floor. The irradiations made during, the GODIVA runs, including the PuBe calibrations, are listed in Table 3. After an initial PuBe source calibration, four steady-state runs were performed, primarily for high-rate calibrations of the detectors to this neutron spectrum. Burst 1 was then attempted, but no LANL burst trigger was provided because of a problem with their monitor. This was followed by the second PuBe calibration and the fifth steady-state run. The burst trigger also failed for bursts 2 and 3 . Bursts $4-8$ were performed successfully with the burst parameters given in Table 3 .

Bursts were used primarily to test the fast-burst capabilities of the three detector systems under evaluation. The pulse-counting and burst monitoring provided by Eberline for the Type $A$ and gamma detectors obtained useful data. The current-sense circuils provided by LLNL for the Type $B$ and $C$ detectors did not perform properly. A large part of the problem was an unexpected polarity reversal of the current-sense signal and difficulties with resetting or adjusting the circuits between bursts.

We attempted to detect a fast burst with the Type $\mathrm{C}$ detector by connecting the detector to a coaxial cable terminated at a fast oscilloscope in the control room. Using a conventional oscilloscope camera, we observed a negative-going pulse with a width of $2 \mathrm{~ms}$; approximately that registered by the LANL burst monitor. However, we did not bias the detector, so the pulse amplitude of several tenths of a volt was not proportional to the peak radiation rate. These results indicated that, with improvements in the electronics and the addition of a bias network, the Type $\mathrm{C}$ detector could provide a reliabie burst-sensing capability. At this time, however, we had not made any effort to separate the response produced by the scintillator from the direct response of the solid-state photodiode to gamma rays.

The sensitivities of the Type $B$ and $C$ detectors measured for the steady-state runs are summarized in Table 4. Sensitivities obtained for the GODIVA spectrum tend to be somewhat higher than those obtained for the more moderated SHEBA spectrum. The Type $\mathrm{C}$ detector again saturated at radiation levels above $1.5 \mathrm{rem} / \mathrm{h}$, which has the effect of reducing the measured sensitivity at the higher reactor powers. No data are available for the Type A detectors in the steady-state runs.

Eberiine measured the time interval between the CODIVA burst and the activation of the high. alarm for the Type A detectors. This time interval varied from $50-500 \mathrm{~ms}$, depending on the burst peakrate and pulse width. The failure of the prototype current-sensi circuits for the Type $B$ and $C$ detectors ruled out obtaining similar data for those detectors.

\section{Discussion}

Because of the late delivery of some of the detectors evaluated in l'hase 1 , we were unable to complete all the planned testing at LLNL before the LANL runs. We did obtain a laboratory NIM monitoring system for the pulse-counting mode, and we designed and fabricated an eight-channel bias supply and prototype burst monitor. Two PuBe source measurements were made at LLNL before the LANL tests, but we had no suitable way to test the burst monitors at LLNL.

Stcady-state and slow-ramp runs at the SHEBA facility were useful to characterize the three detector types tested. The free-evolution SHEBA run, though interesting from a criticality safety viewpoint, contributed little to the tests and resulted in unnecessarily high radiation exposure to the detectors and nearby electronics.

The steady-state and burst runs at the GODIVA faciljty were also useful, but we were able to obtain useful burst data for only the Type $A$ and Type $C$ detectors. The maximum GODIV A burst (burst 8) was useful for timing purposes but was too short $(50 \mu \mathrm{s})$ for realistic simulation of an accidental criticality excursion. This burst also produced an unnecessarily high exposure to the detectors and nearby electronics.

Overall, the LANL tests were very useful. We obtained important data at both SHEBA and GODIVA, as well as valuable feedback for redesigning the burst-monitoring circuits. In addition, we 
learned several lessons about irradiation procedures and operational logistics that were integrated into subsequent testing plans.

\section{Phase II Activities (FY'84)}

\section{General Remarks}

Progress of Phase II activities was summaized in Quarterly Reports 3-6.

Both the Type $A$ and $B$ detectors evaluated during Phase I of this work utilize a solid-state charged-particle detector to monitor charged particles produced by neutrons in an external ${ }^{6} \mathrm{LiF}$ converter. Because of the energy loss of the charged particles as they leave the converler, charged particles of all energies up to the maximum produced by the reaction are recorded. The result is a pulseheight spectrum for which the count above a fixed discriminator setting is almost linearly proportional to that selting. Thus, the sensitivity is affected by any drift in the discriminator setting or changes in amplifier gain.

The Type $C$ detector produces a much better output because it uses reactions between neutrons and ${ }^{6} \mathrm{Li}$ within a scintillator. Excluding edge effects, all of the energy of the charged particles is deposited in the detector. This produces a pulse-height distribution that has a definite peak, normally well separated from the response to gamma rays and noise. Such a pulse-height distribution produces a plateau in the count-rate vs discriminator setting, which is much less sensitive to gain changes or drifts in the discriminator setting.

Based on the superior performance of the Type $C$ detector, we decided to explore this concept further in Phase II of our project. With our sponsor's agreement, we continued to explone how the Type A and $B$ detectors might be improved and to include these detectors in subsequent testing and evaluation. We also decided to investigate the possible use of plastic organic scintillators, both ${ }^{6} \mathrm{Li}$ loaded and unloaded.

Because the scintillators needed for our Phase fI evaluations were specially designed and fabricated after extensive technical collaboration with several commercial vendor personnel, we incurred rather long delivery times. In addition, many of the solid-state photodiodes and vacuum phototubes included in the Phase II evaluations had to be specially ordered, some with long delivery times as well. This produced delays in the assembly, irradiation testing, calibration, and evaluation of the detectors made using these components.

After completing the technical discussions to define the specifications of the detectors and the other components and their fabrication, I was away from LLNL for approximately two months. During this time, I gave a technical paper at the Intemational CODATA Conference in Jerusalem, visited the International Atomic Energy Agency, visiled eight governmental nuclear agencies in England and France, and visited the British Nuclear Fuels Lid. reprocessing plant at Sellafield, England. Technical discussions during these visits produced useful information about nuclear radiation detectors, radiation monitoring and criticality alarm instrumentation, and criticality safety analysis. Because this trip coincided with the delivery lime for the Phase II components, little time was lost from the pursuit of project goals.

\section{Basic Considerations: Type A and B Detectors}

As a basis for detector comparisons and optimization, the approximate range or absorption length for the several particles and materials of interest are shown in Table 5. For the Type A and $B$ detectors, the ranges of the alpha particle $(2.05 \mathrm{MeV})$ and the triton $(2.73 \mathrm{MeV})$ from the the ${ }^{6} \mathrm{Li}(\mathrm{n}, \mathrm{t})$ ajpha reaction are approximately 4.5 and $25 \mu \mathrm{m}$, respectively, in the ${ }^{6} \mathrm{LiF}$ converter. Therefore, an optimum converter thickness would be in the range of $20-30 \mu \mathrm{m}$. This thickness is very difficult to produce. The maximum practical thickness for vacuum deposition techniques is on the order of $0.5 \mu \mathrm{m}$. On the other 
hand, high-pressure, high-temperature mechanical compressinn techniques produce a minimum practical thickness of $250 \mu \mathrm{m}$, and the resulting foil is extremely brittle.

The converters used in the Type A and B detectors were made using mechanical compression but at $750 \mu \mathrm{m}$ thick for better strength. The information in Table 5 shows that such a thickness highly absorbs thermal neutrons. Thus, thermal neutrons incident on the front of the converter will be absorbed before they get close enough to the back of the converter for the resulting charged particles to escape and be detected by the charged-particle detector. However, not all of the neutrons impinging on the converter will be completely thermalized, and thermal neutrons can also enter the converter from the back side; thus, a substantial fraction of the incident moderated neutrons will be detected.

It may be possible to extend vacuum deposition techniques to provide converters of optimum thickness. Unfortunately, the ideas occurring to us that appearsd capable of producing such advances could not be tested.

The reverse-biased silicon diodes used for the Type A and B detectors have depletion depths of 60$100 \mu \mathrm{m}$, which match the alpha and triton ranges in silicon fairly well. Such depletion depths are relatively small compared with the range of the electrons generated by the 1-MeV gamma radiation expected from a criticality excursion.

\section{Improvement of the Type C Detector}

Given the superior performance of the Type $C$ detector: we decided to focus in Phase II on optimizing the ${ }^{6} \mathrm{Lil}(\mathrm{Eu})$ scintillator and its light sensor. Table 5 shows that thermal neutrons will not penetrate more than $2-3 \mathrm{~mm}$ into the ${ }^{6} \mathrm{Lil}(\mathrm{Eu})$ scintillator. These data provide a guide for sclecting an optimum size for the scintillator. While making it greater than $5-10 \mathrm{~mm}$ in any dimension will increase the sensitive area for thermal neutron interactions, larger dimensions will also result in a larger central volume where few neutrons and more gamma rays can interact.

In an attempt to improve the light coupling to the photodiode, we requested Harshaw/Filtrol to fabricate a detector that used a sandwich of a 3-mm-thick slab of ${ }^{6} \mathrm{Lil}(\mathrm{Eu})$ between two glass plates of similar thickness. Two such detectors were fabricated, but both were darnaged in shipping and could not be repaired in time for evaluation in this project. The remainder of our efforts related to ${ }^{6} \mathrm{Lil}(\mathrm{Eu})$ in Phase 11 were directed toward obtaining scintillators sealed in thin-walled aluminum liv-iings with glass windows to allow testing each scintillator with a variety of solid-state photodiodes or vacuum phototubes. Harshaw/Filtrol fabricated these scintillators on special order, which led to long delivery times and the delay of several tests planned for Phase II.

We discussed specifications and availability of both solid-state photodiodes and vacuum phototubes with several commercial suppliers. Solid-state photodiodes were ultimately oblained from three suppliers and vacuum phototubes from two. Some of the items we ordered were new and in short supply, which led to long delivery times. Thus, we began to receive the solid-state and vacuum photodiodes and vacuum phototriodes and phototetrodes near the end of Phase II.

\section{Investigation of Plastic Scintillators}

We had several discussions with Bicron Corporation personnel about the development of various types of plastic organic scintillators. The primary reason for including such scintillators in this project was the reduced fabrication constraints. Plastic scintillators are rugged, non-hygroscopic, easily machined to any size, and relatively inexpensive. The scintillators obtained for this project varied in size, but most were machined as 1-in. diameter by 1 -in. long cylinders.

Sorne of the scintillators were loaded with ${ }^{6} \mathrm{Li}$ to provide a thermai-neutron response so that we could obtain an approximate neutron dose-equivalent (rem) response by enclosing the scintillator and its associated photosensor in an hydrogenous moderator. Unloaded plastic scintillators were included to determine the practicality of providing an approximate neutron absorbed-dose (rad) response via proton-recoil interactions. The basic formulation of the scintillators and the amount of ${ }^{6} \mathrm{Li}$ loading were varied to permit the selection of an optimum combination. 
It should be pointed out that plastic scintillators produce light with considerably less efficiency than ${ }^{6} \mathrm{LiI}(\mathrm{Eu})$ for heavy charged particles. For example, the $4.78 \mathrm{MeV}$ from a thermal neutron interaction with ${ }^{6} \mathrm{Li}$ will produce approximately the same light output as a $3.6-\mathrm{MeV}$ electron in ${ }^{6} \mathrm{LiI}(\mathrm{LiI})$, but only about the equivalent of a $0.5-\mathrm{MeV}$ electron in a plastic scintillator.

Most of the work with these scintillators was actually performed during Phase III of this project. Thus, the various plastic scintillators received and evaluated are described in the Phase III section.

\section{LLNL Laboratory Tests}

Because the components for the improved delectors arrived late, laboratory lests at LLNL during Phase II were concerned primarily with detailed characterization of the Type $A, B$, and $C$ detectors. The measurements were performed using a ${ }^{252} \mathrm{Cf}$ source, both bare and in a $\mathrm{D}_{2} \mathrm{O}$ moderator, and a PuBe source. The PHD, angular dependence, and neutron-energy dependence were measured for each detector. Typical PHDs for the Type A, B, and C detectors are shown in Figs. 7-9, respectively.

The Type A PHD (Fig. 7) is very broad with some indication of two peaks, which are caused by maximumenergy alpha particles $(2.05 \mathrm{MeV})$ and tritons $(2.78 \mathrm{MeV})$. For decreasing pulse heights, the PHD first falls and then rises. This is due to a small amount of charged-particle detector nonlinearity, gamma-ray background, and electronic noise. For the Type B detector, the output pulses from both charged-particle detectors were summed to give th. wtal sensitivity. The resulting PHD (Fig. 8) is similar to that from the Type $A$ detector, but the alpha and triton peaks are more clearly defined because of the better resolution of the charged-particle detectors. For bo:h of these detectors, the optimum setting of a pulse-height threshold is not obvious and depends on the gamma-ray background.

As before, the thermal peak produced by the $4.78 \mathrm{MeV}$ total charged-particle energy deposiled in the Type $C$ detector is well defined and separated from the gamma-ray background and noise. However, a double peak was obtained, which indicates that the detector was damaged after the LANL tests, most likely during shipment back to LLNL. Either the scintillator had cracked, or it had broken loose from the photodiode. The detector was returned to Harshaw/Filtrol for repair. Unfortunately, the repairs were not completed in time for further work with this detector

The angular dependence of detector sensitivity was measured using a PuBe source at $1 \mathrm{~m}$. Table 6 gives the results for the Type $A, B$, and $C$ detectors. The accompanying diagram shows that wa defined $0^{\circ}$ to correspond to neutrons directed toward the front surface of the thermal detecter. Conversely, $180^{\circ}$ corresponded to neutrons directed towards the back surface, where the polyethylene plug was used to fill the space behind the detector. In each case, the sensitivity varied approximately $10-20 \%$ from front to bark.

A bart: 'uBe source $\left(E_{a v g}=2.71 \mathrm{MeV}\right)$, a bare ${ }^{252} \mathrm{Cr}$ source $\left(E_{a v g}=1.38 \mathrm{MeV}\right)$, and a ${ }^{252} \mathrm{Cf}$ source in a $150-\mathrm{mm}$ thick $\mathrm{D}_{2} \mathrm{O}$ moderator $\left(\mathrm{E}_{\mathrm{avg}}=0.37 \mathrm{MeV}\right)$ were used to measure the energy average dependence of the detect $;$ sensitivities in (counts $/ \mathrm{min}) /(\mathrm{mrem} / \mathrm{h})$. The results are shown in Table 7 . We found no significant differerice in the sensitivities to the two bare sources, but an approximately $50 \%$ greater sensitivity was obtained with the moderated ${ }^{252} \mathrm{Cr}$ source. This increase in sensitivity is typical for remmeters that use a simple spherical moderator of this size.

\section{Phase III Activities (FY85)}

\section{General Remarks}

Except for the results of the Health Physics Research Reactor (HPRR) tests at the Oak Ridge National Laboratory (ORNL), included in this report, progress during Phase III was summarized in Quarterly Repor's 7-10.

We began to receive the specially developed ${ }^{6} \mathrm{Lil}(\mathrm{Eu})$ and plastic organic scintillators and the varicus solid-state photodiodes and vacuum phototubes near the end of Phase II. The remaining components were received during the first few months of Phase liI. Laboratory tests at LLNL were 
begun in December 1984. Because it was damaged during the LANL tests and not repaired until after the ORNL HPRR tests, the original Type $C$ detector was not evaluated further during this project. However, similar detectors with ${ }^{6} \mathrm{Lil}(\mathrm{Eu})$ scintillators were tested, both at LLNL and at the HPRR.

\section{Scintillater Comparisons}

Preliminary studjes of unloaded organic plastic scintillators coupled with both solid-state and vacuum photodiodes were performed in the search for a detector vith an absorbed-dose response. Thesc studies showed that the neutron-produced signals were indistinguishable from the gamma-ray background and electronic noise and were too small to be of any practical use for delecting ambient dose levels.

To provide a common basis for the design of detectors using the various scintillators, we decided to perform a direct comparison of the light outputs they produced when irradiated by gamma rays. For this purpose, we used a photomultiplier that was mounted in a "black box" and :oupled to a TC171 preamp, a NIM linear amplifier and a multichannel pulse-height analyzer. A ${ }^{137} \mathrm{Cs}$ gamme-ray source produced light in each scintillator via Compton interactions. The upper edg: of the pulse-height distribution produced by the Compton-recoil electron distribution was used as the point for comparing the scintillators. Light outputs were normalized to that of a 1-in diameter by 0.5 -in thick ${ }^{6} \mathrm{Lil}(\mathrm{Eu})$ scintillator that was given the arbitrary designation $\$ 1$. The $B C X X X$ designations for the plastic scintillators are the Bicron Corporation types used and represent different proprictary formulations. Results for all these measurements are summarized in Table 8.

Gamma-rays were used to provide an initial screening of the various scintillators because the electrons they produced yield more light for a given energy deposition than the protons, tritons, or alpha particles produced by neutron interactions. Therefore, only those scintillators that produced useful signals for gamma rays could possibiy be expected to be usable neutron detectors. As expected, the unloaded plastic scintillators gave relatively small outputs, and only a few of the loaded plastic scintillators appeared useful. The two specially built 0.5 -in. cubical ${ }^{6} \mathrm{Lil}(\mathrm{Eu})$ scintillators, mounted in windowed cylindrical housings had not yet been delivered when these tests were performed.

We then mounted the more-promising plastic scintillators on silicon or vacuum photodiodes and irradiated the combinations with a PuBe neutron source and a gamma-ray source. These measurements showed that the inherent response of the silicon photodiodes to gamma rays obscured the response of the combinations using them to the neutrons. Pulse-height distributions neasured for the ${ }^{6} \mathrm{LiF}-$ loaded plastic scintillators were quite broad, similar to those from the Type A and B detectors and were not suitable for using pulsi2height discrimination to reject gamma-ray background and electronic noise. The vacuum photodiode ferformed much better with the best plastic scintillators, showing essentially no inherent gamma-ray response. However, the neutron-produced PHDs had the same broad shape obtained with the silicon photodiodes.

The response of a ${ }^{6} \mathrm{Lil}(\mathrm{Eu})$ scintillator coupled with a silicon photodiode was only marginally useful in a mixed neutron/gamma-ray field. Much better results were obtained when the ${ }^{6} \mathrm{Lill}(\mathrm{Eu})$ scintillators were coupled with two types of vacuum photodiodes. We later obtained some newly developed Hamamatsu vacuum phototriodes and phototehodes (one and two dynode photomultiplier tubes) which provided better PHDs but required higher bias voltages.

We made more sophisticated comparisons of the light output of the 1 -in. diameter by $0.5-i n$. high ${ }^{6} \mathrm{Lil}(\mathrm{Eu})$ scinillator, a 0.5 -in. diameter by 0.5 -in. high $\mathrm{BC} 408$ plastic scintillator with a $5 \mathrm{~g} / \mathrm{l}{ }^{6} \mathrm{LiF}$ loading and a similar plastic scintillator with a $10 \mathrm{~g} / \mathrm{l}$ loading. In this case, the scintillators were mounted on the photomultiplier in the black box, and the PHDs measured for irradiations by both a ${ }^{137} \mathrm{Cs}$ gamma-ray source and a PuBe neutron source. Gamma-ray and neutron light outputs were normalized to the Compton-edge and thermal-peak pulse heights of the ${ }^{6} \mathrm{LiI}(\mathrm{Eu})$ scintillator, respectively. The results, given in Table 9, show that the neutron-produced light outpul of the plastic scintillators is about an order of magnitude below the ${ }^{6} \mathrm{Lil}(\mathrm{Eu})$. Relative neutron sensitivities of the three scintillators, again normalized to the $\mathrm{Lil}(\mathrm{Eu})$ response, were $1.00,0.015$, and 0.035 , respectively. 
From tests made using these scintillators coupled with silicon photodiodes and yacuum photodiodes, we concluded that plastic scintillators cannot fulfill the ambient sensitivity requirements of this project. The ${ }^{6} \mathrm{Lill}(\mathrm{Eu})$ scintillators can be used satisfactorily with either solid-state or vacuum photodiodes, but silicon photodiodes, although more compact, have considerably more inherent sensitivity to gamma rays and are more difficult to instrument for monitoring fast-burst excursions. Based on the results of all of these tests, we decided to concentrate the bulk of our final efforts in this project on the use of ${ }^{6} \mathrm{Lil}(\mathrm{Eu})$ scintillators coupled to vacuum phototubes.

For the final series of tests at LLNL, we coupled the 1-in. diameter by 0.5 -in. high ${ }^{6}$ Lil(Eu) scintillator to a Hamamatsu R330-2 vacusm photodiode, to a Hamamatsu R2148 phototriode, and to a Hamamatsu R2149 phototetrode. A mounting fixture was designed and fabricated for the combination using the photodiode to allow measurements with the detector centered in a 10-in. diameter spherical polyethylene moderator with a fitted polyethylene back plug. The photodiod' was sperated with a 12-V bias supply and was connecled to a TC171 preamplifier. A NIM amplifier was used to further amplify the signal which was recorded on a multichannel analyzer. The PHD obtained for an irradiation using a PuLi $\left(E_{\text {avg }}=0.5 \mathrm{MeV}\right)$ neutron average source is shown in Fig. 10 .

Although a greater sysiem gain would be preferted, the thermal peak is well separated from the background and the electronic noise. The neutron sensitivity was measured for this detector using a PuBe source at $1 \mathrm{~m}$. This measurement gave a gross neutron sensitivity of 1400 (counts $/ \mathrm{min}) /(\mathrm{mrem} / \mathrm{h}$ ) using the total area of the thermal peak or a net neutron sensitivity of 1200 (counts $/ \mathrm{min}) /(\mathrm{mrem} / \mathrm{h}$ ) when a Jinearly interpolated background is subtracted from under the peak.

Because we had not designed a mounting fixture for the phototriode and phototetrode, we measured the performance of the ${ }^{6} \mathrm{Lil}(\mathrm{Eu})$ scintillator on these tubes in the black box. The same amplifiers and pulse-height analyzer were used to acquire the data, which was produced by a moderated PuBe source located outside the box. Results of these measurements are shown in Figs. 11-14. In Fig. 11, the PHD is shown for the scintillator coupled to the phototriode with the anode-to-dymode and dynocie-to-cathode potentials both $100 \mathrm{~V}$ (200 V total bias). Figure 12 shows the result for the same detector with the two bias voltages set at $200 \mathrm{~V}$. These results clearly demonstrati: that the phototriode can provide significant gain, depending upon the bias applied.

Similar data taken with the scintillator coupled to the phototetrode are shown in Fig. 13. These data were obtained with the three interelectrode voltages all set $1050 \mathrm{~V}$. Results for interelectrode voltages of $100 \mathrm{~V}$ are given in Fig. 14. As expected, the phototetrode provides still more gain thal the phototriode.

We cid not have sufficient time to pursue the use of the multi-element phototubes further. The gain is a real advantage, but the bias voltages needed would require incorporating a special power supply into the detector package. Such supplies are readily available, however, as compact dc-to-dc converters that are capable of operation from input voltages in the $6-1012-V$ range.

\section{Burst Monitor Development}

Design of a circuit to monitor the current through the detectors as a means of sensing fast criticality excursions was begun in Phase II and completed in Phase III. The load resistor in the TC171 preamplifier is composed of $100-\mathrm{M} \Omega$ and $10-\mathrm{M} \Omega$ resistors in series. We designed a current monitor that senses the voltage across the $10-\mathrm{M} \Omega$ resistor. The preamplifier housing was modified to provide connections to this resistor via a coaxial feedthrough. Based on our previous experience with the various detector types, we designed this current monitor primarily for use with vacuum photodiodes. Later attempts to use this monitor with the Type A, B, and C deteclors met with little success.

Current through the 10-M $\Omega$ resisitor is sensed by an Analog Devices $290 \mathrm{~A}$ isolation amplifier. The output of the isolation amplifier is further amplified by an integrated-circuit operational amplifier. Appropriate biasing and zero-offset networks are also included (Fig. 15). Signal connection to the preamplifier is made using a short coaxial cable connected to the special input jack (J3 in Fig. 15). The \pm 12 and \pm 24 voltages required by the circuit are provided via a shielded multiconductor cable attached to the NIM-bin power supply. To provide the lowest possible noise, we took special care to filter electrical noise from the isolation amplifier, the power supply, and other sources. Photodiode ambient 
dark cuirent is balanced out of the signal by adjusting potentiometers R8 and R12. The output signal is routed to a coaxial connector ( $j 4$ in Fig. 15). Unlike the circuit used in Phase I, this circuit has no threshold discriminator. We determined the sensitivity of the curnent monitor circuit by measuring the nutput voltage as a function of radiation rate. A voltage level to use as a threshold for burst-excursion detection could be determined later from these data.

At LLNL, a step-input current source was used to measure the time response of this circuit. An effective risetime of $B \mathrm{~ms}$ was obtained. The sensitivity of the output voltage to photodiode current was $2.4 \mathrm{~V} / \mathrm{nA}$.

We fabricated nine current monitors and modified nine TC17l preamps for the HPRR off-sitr irradiation tests. To record the output of the current monitors for fast-burst radiation excursions, we borrowed four dual-channel fast-digitizers from another group at LLNL. All of these systems were carefully checked and calibrated at Livermore and were found to operate satisfactorily.

\section{Monitoring and Bias Instrumentation}

For nulse-counting measurements, we upgraded the NIM-based $\mathrm{PCl}$ systerns originally used for the Los Alamos off-site irradiation tests. The main change was the addition of several new high-gain, laboratory-grade aniplifiers to provide eight high-quality channels. A sumıning amplifier was also included to sum the amplified signals from the two charged-particle detectors of the Type B detector so that only one SCA and scaler would be needed for this detector.

The burst-monitoring instrumentation consisted of the nine new curnent monitors described in "Burst Monitor Development," above. Their outputs could be measured by volt meters, oscilloscopes, chart recorders, and digitizers.

We rebuilt the eight-channel bias power supply. The output-voltage filtering was improved, and the voltage discriminators and LED readorts used in the Los Alamos tests were removed. We added independent polarity switches for each channel but retained the individual voltage adjustments. Finally, we added a high-impedance digital voltmeter with an eight-position switch on its input to make adjustments and verification of the voltages on each channel mone converient.

\section{HPRR Off-Site Irradiation Tests}

The Health Physics Research Reactor is located at the DOSAR Facility of the Oak Ridge National Laboratory. It is a modified version of the Los Aiamos SODIVA II reactor, with the major modification being the addition of 10 wt- $\%$ of molybdenum to the $93.14 \%$ enriched $235 \mathrm{U}$ core. This allowis operation at higher power than that pussible at CODIVA. The reactor is located in a lowscatter building and is operated remotely from a control building about $900 \mathrm{ft}$ away. Contir.uous steadystate operation up to $1 \mathrm{~kW}$ is possible, or short runs up to $10 \mathrm{~kW}$. Operated in the "fast-burst" mode the reactor can produce pulses of up to $1 \times 10^{17}$ fissions that last $60 \mu$ s. The neutron-to-gamma dose ratio is about 10, with a fast neutron dose of about 3.3 tissue rad per hout per watt at one meter. Steel, lucite, and concrete shields exist to modify the neutron spectra.

Steady-state runs, exponentially increasing ramps, and fast-burst excursions were performed at the HPRR from 22-30 July 1985. The first two days involved unpacking, setting up, and performing extensive electrical checks. A first set of calibrations using sources was made on 24 July. Irradiations with the bare HPRR lasted from 24-29 July. On 30 July, we made a second set of calibrations and performed runs with a 12 -cm-thick lucite shield between the reactor and the detectors. The lucite moderated the spectrum and provided a lower average neutron energy.

We planned to use the detectors described in Table 10 during the HPRR measurements. This table identifies the detectors by number, lists the muderators used to provide a dose-equivalent response, and gives the required bias voltages. Detectors 1-3 were previously identified as Types $A, B$, and C, respectively. Detectors 1, 2, and 4-9 were each equipped with a current monitor whose output was recorded on a strip-chart recorder. The $\mathrm{PCl}$ system was used to monitor the count-rate signals from detectors 1,2 , and $4-8$ during calibrations with sources, steady-state reactor runs, and ramps where the reactor power increased exponentially. Detector 3 was not repaired in time to be included in these 
measurements. Based on laboratory measurements with similar detectors, we expented little response from detectors 10 and 11 and obtained no data. Detector 12, supplied by the HPRR facility, was used to monitor the gamma-ray output of the reactor. These data, coupled with the gamma calibrations of our detectors, allowed us to make approximate corrections for the gamma responses of our detectors.

For the runs made with the bare reactor, the detectors were localed on a $100^{\circ}$ are at $6 \mathrm{~m}$ from the reactor and $1 \mathrm{~m}$ above the floor. Before starting the reactor runs on 24 July, the detectors were calibrated using a PuBe neutron source and a ${ }^{137} \mathrm{Cs}$ gamma-ray source, both of which provided by ORNL. These results are given in Table 11. The source yields and dose-conversion factors were also provided by ORNL. A large response is shown for the bare solid-state photodiode (Detector 4). Detector 9, which we planned to use as a monitor, was designed to be identical with Detector 5, but the large difference in the calibrations of the two detectors cast doubt on the performance of Detector 9. Most likely the light coupling between the scintillator and the photodiode was damaged during shipping.

A set of data was taken on 24 July to measure the response of the detectors as a function of reactor power for powers at decade intervals from $0.01-100 \mathrm{~W}$. For all the steady-state runs, at least five count-rate values were recorded for each detector at each reactor power. We averaged these values and used Chauvenet's criteria to reject suspect points. UIsing reactor power values obtained from the reaclor instrumentation and dose-vs-distance values provided by ORNL, average count-rate values were converted to efficiencies in (counts $/ \mathrm{min}) /(\mathrm{mrem} / \mathrm{h}$ ). Figure 16 shows results for the case where the gamma response has been subtracted. The count-rate limitations of the more sensitive detectors are apparent. These data were taken primarily to insure that all the detector systems were working as expected. We did not obtain current monitor data.

We took considerably more data on 25 July, again with the bare reactor running at fixed powers. In this case, however, we ran more reactor powers: $0.01,0.03,0.1,03,1,3,6,10,20,40,60,80$, and $100 \mathrm{~W}$. Figure 17 gives the results for these runs. The results are essentially the same as those in Fig. 16, with the most interesting being those for the Li-loaded plastic scintillator, Delector 8 , which increase witit increasing, power. We interpret this as the effect of the pileup of recoil proton signais in the plastic scintillator at high dose rates. Current monitor data obtained during these runs are shown in Fig. 18. The current signai from Detector $l$ is not significantly greater than zero at these powers.

The detector count-rate outputs were followed for five minutes after the reactor was scrammed from the 100-W run. We encountered no surprises. At thus point, none of the detectors showed evidence of activation or significant damage.

A run for which the reactor power increased exponentially from 1-100 $\mathrm{W}$ with a 100-s period was run on 25 July. The results (Fig. 19) were consistent with the steady-state runs. Detectors 1 and 2 showed small amounts of saturation while Detector 8 showed little saturation, and no obvious overresponse. Detectors 5,6 , and 7 saturated at $10-20 \mathrm{~W}$ but showed no decreases in count rates at the maximum reactor power.

Current monitor responses to ramps run on 25.26 , and 29 July were quite good (Fig. 20). A number of ramps had to be run to get results for all of the detectors because only two strip-charl recorders were available to record the data. The signal from Delector 1 went above zero at about $100 \mathrm{~W}$. Signals from Detectors 5, 6, and 7 crossed zero at 20-30 W, but their response saturated at just over $100 \mathrm{~W}$. The current output from Detector 8 became greater than zero at aboul $10 \mathrm{~W}$ and was nearly linear up to $1000 \mathrm{~W}$. In general, the current monitors exceeded zero at about the same powers at which the count-rate responses of the detectors were saturating.

On 30 July 1985, a $12-\mathrm{cm}$-thick lucite shield was placed on an arc at $2 \mathrm{~m}$ from the reactor. The detectors were then placed on a $100^{\circ}$ arc at $3 \mathrm{~m}$ from the reactor and $1 \mathrm{~m}$ above the floor. A second set of neutron and gamma calibrations was made, for which the results are also given in Table 11. Except for Detector 2, we found little change in the calibration factors. Apparently, one of the diodes in Detector 2 had failed by this time.

Data were taken for steady state runs at $0.01,0.03,0.1,0.3,1,3,10,30,100,300$, and $1000 \mathrm{~W}$. The higher powers could be run because of the shielding provided by the lucite. As before, we reduced the data using conversion factors provided by ORNL specific to this spectrum. The results, given in Fig. 21, are esseritially the same as those obtained with the bare reactor. Detector saturation is more pronounced at the higher powers. The response of Detector 8 reaches a peak and then starts to saturate. 
Current monitor results for these runs are shown in Fig. 22. Obvious zero and gain drift problems can be seen in these data.

Results for an exponential ramp with a 100-s period, beginging at 1 W, are shown in Fig. 23, which confirm the steady-state results. The corresponding current monitor data (Fig. 24) are better than those obtained for the steady-state runs because the systerns har. teen rezeroed. A limited number of recorder channels required running several ramps to obtain the data.

The remainder of the time at the HPRR was used making exposures to fast bursts. Problems with the puise digitizers precluded any uscful data from being obtained from these runs. Oscilloscope measurements also showed that the circuits used in the curreat monitors were too slow to provide good data for excursions as fast as those produced by the HPRR.

Even without satisfactory fast-burst data, the measurements made at the HPRR confirmed the possibility of using these detectors in neutron fields covering a wide range of intensitics. While improvements to the current monitor circuits must be made, the circuits worked as expectid, and provided some overlap with the count-rate response of the detectors. Optimizing the electronics could also increase the usable count-rate range of the detectors. However, the slow decay of the light produced in ${ }^{6}$ Lil(Eu) would limit the amount of improvement possible. For each of the ${ }^{6}$ Lil(Eu) detectors, the saturation couid be described by an equivalent dead time for which consistent values were calculated over all of the sets of steady-state runs. These dead times were all on the order of 10-13 $\mu$ s.

\section{Overall Project Results and Conclusions}

This project allowed us to study severat promising meutron detector systems for applications in criticality monitoring systems. Predominantly, we studied thermal-neutron detectors designed to be run in a polyethylene moderator sphere to provide an approximate dose-equivalent response, although a few of the detectors we tested had approximate absorbed-dose responses. The latter are more consistent with criticality safety standards, which are given in terms of absorbed dose (rads) rather than dose equivalent (rems).

The detectors that measured absorbed dose consisted of various sizes of plastic scintillators mounted on photodiodes. None of these produced usable signals for neutron dose levels that could be conveniently produced in the laboratory. Since they wrre not good for measuring ambient dose levels. these detectors did not meet one of the goals of this project.

All of the dose-equivalent detectors rclied on the interaction of thermal neutrons with ${ }^{6} \mathbf{L i}$, which produces an alpha particle and a triton with a minimum total kinetic energy of $4.78 \mathrm{MeV}$. Pressed disks of ${ }^{6} \mathrm{LiF}$ were used in two of the detector systems: in one case they were coupled with a single semiconductor charged-particle detector, and in the other case they were placed between two such detectors. Other detectors used $6_{\mathrm{LiF}}$ mixed into a plastic scintillator with the light detected by a vacuum photodiode. Still others consisted of 'Lil(Eu) scintillators coupled to photodiodes. Both semiconductor and vacuum photodiodes were used, and a few preliminary tests with phototriodes and phototetrodes were also made.

For some of the tests of the single-diode, converter-disk detector, electronic systems provided by the manufacturer were used. For most of the tests, however, we used combinations of commercially available instruments and special circuits designed and built at LLNL. Standard NIM clectronic components were used in most cases to amplify the signals produced by the detectors, but the bias supplies and current monitoring circuits were locally produced.

Detector comparisons were made in the laboratory using several different isotopic neutron and gamma sources. In addition, tests were made at critical facilities at LANL and ORNL. The most promising neutron detector that met the requirements established for this project consisted of a $10-\mathrm{mm}$ cubical ${ }^{6} \mathrm{Lil}(\mathrm{Eu})$ scintillator operated on a vacuum photodiode. A similar scintillator mounted on a solid-state photodiode also produced a usable response to neutrons, but such photodiodes exhibit considerable sensitivity for the direct detection of gamnna rays. Coupling the scintillator to photomultupticr tubes with one or Iwo dynodes (phototriodes or phototetrodes) produced very favorable results but would require local high-voltage supplies of several hundred volts for their use. 
However, these high voltages are of the same order as those needed with the GM detectors commonly used in criticality detectors.

The comparisons obtained between the response of the detectors for the laboratory sources and the fission assemblies at LANL and ORNL were not exceptional. While not all of the variation can be explained, some is the result of the variety of monitoring systems used for the different experiments and differences in the neutron spectra encountered. Disagmement in the factors used to convert neutron fluences to doseequivalent values ray also account for some of the variation. It is, of course, always more difficult to get top-quality data during measurements at off-site facilities.

Deficiencies were discovered in the circuits used to sense the current through the detectors at high dose-equivalent rates. Better sensitivity. higher inpul isolation, and faster response would be desirable. Fortunately, the state of the art in integrated-circuit isolation amplifiers has already advanced to the point where such improvernents are possible.

Thus, a dose-equivalent sensitive detector, with sufficient sensitivity to measure ambient neutron levels, can be built for use as a romponent of a criticality alarm system. Based on our results, the unit should consist of a $10-\mathrm{mm}$ cubic ${ }^{6} \mathrm{Lil}(\mathrm{EU})$ scintillator mounted on a vacuum photodiode and located in a 10-in. diameter polyethylene spherical moderator. The pulses produced by this detector should be amplified with a compact, low-noise preamplifier and amplifier. Logic-type signals can be produced by feeding the amplifier signals into a single channel pulse-height analyzer. Intense signals can be detected by measuring the current through the photodiode. Both of these outputs are consistent with the inputs of currently available criticality alarm systems.

\section{Recommendations for Future Developments}

This project was based on the assumption that adding neutron detectors with a dose-equivalent response to a criticality monitoring system was desirable. Within the constraints established for this project, the system we have described appears to be an optimum. However, some problems identified by this work remain unresolved.

The current-monitor cirsuits should be improved. By using better integrated circuits it should be possible to achieve higher sensitivity with better input isolation, faster response, and more stability.

The use of phototriodes and phototetrodes should he studied further. Readily available, compact dc-to-dc converters could be used to supply the power necessary for tt.air operations to avoid having to transmit high voltages to each detector assembly. With such supplies it would also be possible to use even more sophisticated photomultiplier tubes, thus reducing the need for high-gain, low-noise pulse amplifiers.

Performance of the detectors might be improved if the scintillators were coupled directly to the phototube, with the two constructed as an integral unit. This would eliminate the glass window used in the prototype detectors and decrease the chance of light loss between the scintillator and the phototube.

Several improvements could be made in the pulse amplifiers and associated electronics. A lownoisc preamplificr oftimized for high counting rites rev!d the decirable. Designing a compact system that includes the preamplifier, linear amplifier, single-channel analyzer, and high voltage supply (if needed) would make the system easier to install in the field.

One limitation to the widespread application of these detectors to criticality alarm systems is the difficulty of obtaining the ${ }^{6}$ Lil(Eu) scintillator, their high cost, and their fragility. Perhaps alternate sources of these scintillators could be found that would alleviate some of these problems.

Finally, we were nol able to complete all of the environmental tests, such as vibration, temperature, and shock, that should be done before recommending such a system for widespread application. In addition, thorough calibrations with a wide variety of neutron spectra, reactor periods, and neutron-to-gamma ray ratios should be performed. Some of this information might be oblained through computations. 


\section{Acknowledgments}

The principal investigator is pleased to a:knowledge the assistance of other LLNL personnel in this project. Special thanks is due John Thomgate for his many helpful suggestions during the detector development, for performing electronic and radiation tests at LLNL, for providing his pulsed-source remmeter for use as the neutron monitor at the LANL irradiation tests, for his support in preparing the detectors and analyzing the data for the Oak Ridge HPRK itradiation tests, for his interim summarics that have been incorporated into the present report, and for his help in completing this report. Thanks are also due to Tom lenkins who designixu and supervised the fouricanon of a spirial detexier power supply and the vartous burst-monitoring circuitry used in this project and who assisted in the HPRR irradiation tests. The principal investigator also thanks Bob Kaifer for his guidance and suggestions in the design of the LLNL circuitry, Duane Rueppel for his assistance at the LANL irradiation tests, and Don Salmi for the mechanical fabrication of various detector components, indluding the spherical polyethylene moderators. Special thanks are dus 10 Kevin Anderson for editing this report and preparing the figures and tables for final production.

The principal investigator also expresses his thanks for the cooperation and support provided by Dick Malenfant and his staff Juring the LANL tests and by Steve Sims and his staff during the HPRR tests. Special gratitude is extended to Steve Willhoite and his coworkers from Eberline Instrument Corporation for furnishing personnel assistance and a complete Eberline digital Criticality Alarm System (similar to the new LLNL standard system) for the LANL tests.

Finally, the principal investigator thanks our sponsor, Blake Brown, U. S. Department of Energy, Office of Nuclear Safety, for his support and encouragement and for providing the funding for the project; and also for his kind patience and understanding regarding the delay of this final project report due to the extended illness of the principal investigator. 
Table 1. SHEBA runs and Pu-Be calibration.

\begin{tabular}{cllcc}
\hline Run & Date & Run Type & Neutron (mrem/hr) & Gamma (mr/hr) \\
\hline & & & & \\
\hline 1 & $8 / 30 / 83$ & Steady State & 94 & 10 \\
2 & $8 / 30 / 83$ & Steady State & 91 & 10 \\
3 & $8 / 30 / 83$ & Ramp ( 200 s) & $91-280$ & $10-30$ \\
4 & $8 / 30 / 83$ & Steady State & 275 & 30 \\
5 & $8 / 30 / 83$ & Ramp & $270-1230$ & $30-125$ \\
6 & $8 / 30 / 83$ & Steady State & 1230 & 125 \\
7. & $8 / 30 / 83$ & Decay Shutdown & n.a. & n.a. \\
8. & $8 / 31 / 83$ & Ramp ( - 56 s) & n.a. & n.a. \\
9 & $8 / 31 / 83$ & Ramp ( 120 s) & n.a. & n.a. \\
10 & $8 / 31 / 83$ & Free-Evolution & n.a. & n.a. \\
Pu-Be & $8 / 31 / 83$ & Calibration & 21.2 & \\
\hline
\end{tabular}

Table 2. Measured sensitivity (cpm/(murem/h)): SHEBA sleady-state runs and Pu-Be calibration.

\begin{tabular}{|c|c|c|c|c|c|}
\hline $\begin{array}{l}\text { Neutron } \\
\text { detector }\end{array}$ & $\begin{array}{l}\text { Run } 1 \\
\text { ( } 54 \text { mrem/hr) }\end{array}$ & $\begin{array}{l}\text { Run } 2 \\
\text { (91 mrem/hr) }\end{array}$ & $\begin{array}{l}\text { Run } 4 \\
(278 \mathrm{mrem} / \mathrm{hr})\end{array}$ & $\begin{array}{l}\text { Run6 } \\
(1320 \text { mrem/hr) }\end{array}$ & $\begin{array}{l}\text { Pu-Be } \\
\text { (21.1mrem/hr) }\end{array}$ \\
\hline$A 2$ & n.a. & 12.0 & 11.1 & 11.2 & n.a \\
\hline A4 & n.a. & 11.3 & 10.9 & 11.4 & 9.38 \\
\hline A6 & n.a. & 10.7 & 9.14 & 10.3 & n.a. \\
\hline B 1 & 34.8 & 35.2 & 34.9 & 10.3 & n.a. \\
\hline B2 & 36.5 & 36.3 & 36.0 & 36.4 & 30.1 \\
\hline C & 706. & 716. & 706. & 637. & 626. \\
\hline
\end{tabular}


Table 3. GODIVA runs and Pu-Be calibrations.

\begin{tabular}{|c|c|c|c|}
\hline Run & Date & Run type & $\begin{array}{l}\text { Parameters and } \\
\text { comments }\end{array}$ \\
\hline Pu-Be & $9 / 1 / 83$ & Calibration & Pu-Be $18.3 \mathrm{mrem} / \mathrm{hr}$ \\
\hline 1 & $9 / 1 / 83$ & Steady State \#1 & $13.0 \mathrm{mrem} / \mathrm{hr}$ \\
\hline 2 & $9 / 1 / 83$ & Steady State $\$ 2$ & 174. mrem/hr \\
\hline 3 & $9 / 1 / 83$ & Steady State $\# 3$ & 1620. mrem/hr \\
\hline 4 & $9 / 1 / 83$ & Steady State $\# 4$ & 16650. mrem/hr Detector $C$ paralyzed \\
\hline 5 & $9 / 1 / 83$ & Burst *1 & No LANL trigger \\
\hline Pu-Be & $9 / 2 / 83$ & Calibration & $\mathrm{Pu}-\mathrm{Be} 19.3 \mathrm{mrem} / \mathrm{hr}$ \\
\hline 6 & $9 / 2 / 83$ & Steady State $\# 5$ & 2000. mrem $/ \mathrm{hr}$ Detector C disconnected \\
\hline 7 & $9 / 2 / 83$ & Burst \#2 & No trigger, $\Delta \mathrm{T}=68^{\circ} \mathrm{C} \quad$ Detector $\mathrm{C}$ to scope \\
\hline 8 & $9 / 2 / 83$ & Burst $\# 3$ & No trigger, $\Delta \mathrm{T}=50^{\circ} \mathrm{C}, \tau=160 \mu \mathrm{s}$ \\
\hline 9 & $9 / 2 / 83$ & Burst \#4 & $\begin{array}{l}\Delta \mathrm{T}=45^{\circ} \mathrm{C}, 8.3 \times 10^{10} \text { fiss., } \gamma=3 \mathrm{rad}, \\
\mathrm{n}=18 \mathrm{rad}, \tau=195 \mu \mathrm{s}\end{array}$ \\
\hline 10 & $9 / 2 / 83$ & Burst $\# 5$ & $\begin{array}{l}\Delta \mathrm{T}=51^{\circ} \mathrm{C} 9.4 \times 10^{15} \text { fiss., } \gamma=3 \mathrm{rad}, \\
\mathrm{n}=20 \text { rad, } \tau=175 \mu \mathrm{s}\end{array}$ \\
\hline 11 & $9 / 2 / 83$ & Burst $\$ 6$ & $\begin{array}{l}\Delta \mathrm{T}=35^{\circ} \mathrm{C}, 6.5 \times 10^{15} \text { fiss., } \gamma=2 \text { rad, } \\
\mathrm{n}=14 \mathrm{rad}, \tau=270 \mu \mathrm{s}\end{array}$ \\
\hline 12 & $9 / 2 / 83$ & Burst \#7 & $\begin{array}{l}\Delta \mathrm{T}=30^{\circ} \mathrm{C}, 5.6 \times 10^{15} \text { fiss., } \gamma=2 \mathrm{rad} \\
\mathrm{n}=12 \mathrm{rad}, \tau=450 \mu \mathrm{s}\end{array}$ \\
\hline 13 & $9 / 2 / 83$ & Burst $\# 8$ & $\begin{array}{l}\Delta \mathrm{T}=223^{\circ} \mathrm{C}, 4.1 \times 10^{16} \text { fiss. } \gamma=15 \mathrm{rad}, \\
\mathrm{n}=90 \mathrm{rad}, \tau=240 \mathrm{\mu s}\end{array}$ \\
\hline
\end{tabular}

$\Delta \mathrm{T}=$ GODIVA temperature excursion

$\gamma=$ gamma dose

n = neutron dose

$\tau=$ burst width (FWHM) 
Table 4. Measured sensitivity (cpm/(mrem/h)): GODIVA steady-state runs and Pu-Be calibration.

\begin{tabular}{|c|c|c|c|c|c|c|}
\hline $\begin{array}{l}\text { Neutron } \\
\text { detector }\end{array}$ & $\begin{array}{l}\text { Pu-Be } \\
(18.3 \mathrm{mrem} / \mathrm{h})\end{array}$ & $\begin{array}{l}\text { Run } 1 \\
\text { (13.0 mrem/h) }\end{array}$ & $\begin{array}{l}\text { Run } 2 \\
\text { (174. mrem/h) }\end{array}$ & $\begin{array}{l}\text { Run3 } \\
\text { (1620. mrem/h) }\end{array}$ & $\begin{array}{l}\text { Pu-Be } \\
(19.3 \mathrm{mrem} / \mathrm{h})\end{array}$ & $\begin{array}{l}\text { Run } 6 \\
(200 . \text { mrem/h) }\end{array}$ \\
\hline$B 1$ & 41.7 & 49.3 & 38.4 & 36.2 & $95.9^{*}$ & 33.7 \\
\hline$B 2$ & 34.5 & 37.3 & 36.5 & 36.0 & $43.2^{\prime \prime}$ & 32.9 \\
\hline$C$ & 682. & 754. & 815 & $319^{+}$ & n.a & n.a. \\
\hline
\end{tabular}

- High residual background radiation level

- Temporary blind-out at high radiation levels

Table 5. Charged-particle ranges and thermal-neutron absorption lengths in ${ }^{6} \mathrm{LiF},{ }^{6} \mathrm{Lil}$ (Eu), and $\mathrm{Si}$.

\begin{tabular}{|c|c|c|c|c|}
\hline \multirow[b]{2}{*}{ Particle } & \multirow[b]{2}{*}{ Energy } & \multicolumn{3}{|c|}{ Approximate range or absorption length ( $\mu \mathrm{m})$} \\
\hline & & ${ }^{6} \mathrm{LiF}$ & ${ }^{6} \mathrm{LiI}(\mathrm{Eu})$ & Si \\
\hline Alpha & $2.05 \mathrm{MeV}$ & 4.5 & 6 & 8 \\
\hline Triton & $2.73 \mathrm{MeV}$ & 25 & 33 & 45 \\
\hline Electron & $0.5 \mathrm{MeV}$ & - & - & 600 \\
\hline Electron & $1.0 \mathrm{MeV}$ & - & - & 1500 \\
\hline Nieutron & $0.025 \mathrm{eV}$ & 200 & 600 & $125 \mathrm{~m}$ \\
\hline
\end{tabular}


Table 6. Angular dependence of detector sensitivities (Pu-Be source al $1 \mathrm{~m}$ ).

\begin{tabular}{cccc}
\hline Angle & Type A & $\begin{array}{l}\text { Sensitivity } \\
\text { Type } \text { B }^{*}\end{array}$ & $\begin{array}{c}\text { (cpm/(mrem/h)) } \\
\text { Type C }\end{array}$ \\
\hline $0^{\circ}$ & $19.5 \pm 0.6$ & $24.6 \pm 0.4$ & 694.6 \\
$45^{\circ}$ & $19.4 \pm 0.6$ & $22.1 \pm 0.4$ & 680.6 \\
$90^{\circ}$ & $18.1 \pm 0.6$ & $21.0 \pm 0.4$ & 681.6 \\
$135^{\circ}$ & $17.1 \pm 0.5$ & $18.9 \pm 0.4$ & $680 . \pm 6$ \\
$181 r^{\circ}$ & $17.4 \pm 0.6$ & $19.2 \pm 0.4$ & 706.66 \\
\hline
\end{tabular}

- Surr of counts fram both CPDs

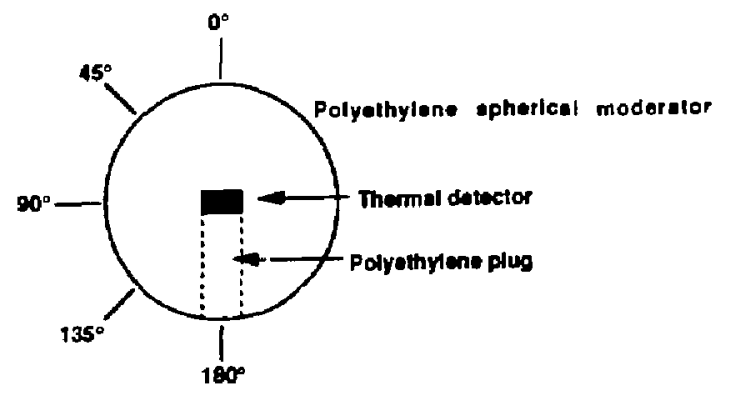

Table 7. Neutron energy dependence of detector sensitivity.

\begin{tabular}{lccc}
\hline & \multicolumn{3}{c}{ Sensitivity (cpm/(mrem/h)) } \\
$\begin{array}{l}\text { Detector } \\
\text { tyre }\end{array}$ & $\begin{array}{c}\text { Pu-Be } \\
\left(E_{\text {avg }} \times 2.71 \mathrm{MeV}\right)\end{array}$ & $\begin{array}{c}{ }^{252} \mathrm{Cf} \\
\left(E_{\text {avg }}=1.38 \mathrm{MeV}\right)\end{array}$ & $\begin{array}{l}252 \mathrm{Cf}+150 \mathrm{~mm} \mathrm{D}_{2} \mathrm{O} \\
\left(\mathrm{E}_{\text {avg }}=\mathbf{0 . 3 7} \mathrm{MeV}\right)\end{array}$ \\
\hline & 12.7 & 13.3 & 18.3 \\
A & 15.2 & 15.3 & 20.5 \\
C & 501. & 524. & 730. \\
\hline
\end{tabular}

* Sum ol counts from both CPDs 
Table 8. Scintillation fluor light-output comparison ( ${ }^{137} \mathrm{Cs}$ gamma-ray source).

\begin{tabular}{|c|c|c|}
\hline Fluor type/size & Loading & $\begin{array}{l}\text { Relative light } \\
\text { output }\end{array}$ \\
\hline${ }^{6} \mathrm{Lil}(\mathrm{Eu} / 1 " \mathrm{dia} \times 0.5 " \quad \#]^{*}$ & - & 1.000 \\
\hline${ }^{6} \mathrm{Lil}(\mathrm{Eu} / 1$ "dia $\times 0.5 " \# 2$ & - & 0.934 \\
\hline${ }^{h}(\mathrm{Li}\langle\mathrm{Eu}) / 4 \mathrm{~mm}$ dia $\times 4 \mathrm{~mm}$ & - & 0.636 \\
\hline fLi Glass $/ 10 \mathrm{~mm}$ dia $\times 10 \mathrm{~mm}$ & - & 0.325 \\
\hline BC430)/1.3"dia X 1.3"\#1 & none & 0.093 \\
\hline $8 C 430 / 1.3 "$ dia $\times 1.3^{\prime \prime} \# 2$ & none & 0.106 \\
\hline $\mathrm{BC} 430 / 1^{\prime \prime d i a ~} \times 1^{\prime \prime} \# 1$ & none & 0.126 \\
\hline $\mathrm{BC} 430 / 1^{*}$ dia $\times 1^{\prime \prime} \# 2$ & none & 0.139 \\
\hline BC430/0.7"dia $\times 0.7 " \# 1$ & none & 0.146 \\
\hline BC430/0.7"dia $\times 0.7 " \# 2$ & none & 0.139 \\
\hline BC408/1"dia $\times 1 "$ & $2.5 \mathrm{~g} / /^{6} \mathrm{LiF}$ & 0.987 \\
\hline $\mathrm{BC} 408 / 1 " \mathrm{dia} \times 1 "$ & $5.0 \mathrm{~g} / 1^{6} \mathrm{LiF}$ & 0.907 \\
\hline BC408/1"dia × 1" & $10.0 \mathrm{~g} / 1^{6} \mathrm{LiF}$ & 0.907 \\
\hline BC408/1"dia $\times 1 "$ & $15.0 \mathrm{~g} / 1^{6} \mathrm{LiF}$ & 0.775 \\
\hline $\mathrm{BC} 408 / 1 "$ dia $\times 1^{\prime \prime} \# 1$ & ${ }^{6} \mathrm{LiF}$ in reflector paint & 0.934 \\
\hline BC408/1"dia × 1" \#2 & ${ }^{6} \mathrm{LiF}$ in reflector paint & $0.94 \%$ \\
\hline $\mathrm{BC} 408 / 1 " \mathrm{dia} \times 0.040^{\prime \prime} \# 1$ & $210 \mathrm{~g} / 1^{6} \mathrm{LiF}$ & 0.503 \\
\hline $\mathrm{BC} 4(08 / 1 " \mathrm{dia} \times 0.040 " \# 2$ & $210 \mathrm{~g} / 1^{6} \mathrm{LiF}$ & 0.503 \\
\hline BC412/1"dia $\times 1 "$ & $2.5 \mathrm{~g} / 1^{6} \mathrm{LiF}$ & 0.901 \\
\hline BC412/1"dia $\times 1^{*}$ & $5.0 \mathrm{~g} / 1^{6} \mathrm{LiF}$ & 0.755 \\
\hline $\mathrm{BC}+12 / 1$ "dia $\times 1$ " & $10.0 \mathrm{~g} / 1^{6} \mathrm{LiF}$ & 0.470 \\
\hline BC $\$ 28 / 1$ "dia $\times 1 "$ & $2.5 \mathrm{~g} / 1^{6} \mathrm{LiF}$ & 0.523 \\
\hline BC428/1"dia × 1" & $5.0 \mathrm{~g} / 1^{6} \mathrm{LiF}$ & 0.444 \\
\hline BC428/1"dia $\times 1$ " & $10.0 \mathrm{~g} / 1^{6} \mathrm{LiF}$ & 0.338 \\
\hline BC428/1"dia $\times 1 "$ & $25.0 \mathrm{~g} / 1^{6} \mathrm{LiF}$ & 0.199 \\
\hline BC $454 / 1^{\prime \prime}$ dia $\times 1 "$ & 5\%(wt.) natural B & 0.815 \\
\hline
\end{tabular}


Table 9. Relative light outpui for selected fluors using gamma-ray and neutron sources.

\begin{tabular}{|c|c|c|}
\hline \multirow[b]{2}{*}{ Scintillation fluor } & \multicolumn{2}{|c|}{ Relative light output } \\
\hline & Gamma rays & Neutrons \\
\hline${ }^{6} \mathrm{Lil(Eu)/1"dia} \times 0.5 "$ thick & 1.00 & 1.00 \\
\hline $\mathrm{BC} 408 / 0.5^{\prime \prime} \mathrm{dia} \times 0.5^{\prime \prime} / 5 \mathrm{~g} / 1^{6} \mathrm{LiF}$ & 0.78 & 0.11 \\
\hline BC408/0.5"dia $\times 6.5^{\prime \prime} / 10_{\mathrm{g}} / \mathrm{I}^{6} \mathrm{LiF}$ & 0.81 & 0.11 \\
\hline
\end{tabular}

Table 10. Detectors planned for HPRR irradiation tests.

\begin{tabular}{|c|c|c|c|}
\hline $\begin{array}{l}\text { Detector } \\
\text { number }\end{array}$ & Detector type/description & $\begin{array}{l}\text { Polyethylene } \\
\text { moderator }\end{array}$ & $\begin{array}{l}\text { Bias } \\
\text { (volts) }\end{array}$ \\
\hline 1 & Type A ( ${ }^{6} \mathrm{LiF}$ converter/Diffused Junction CPD) & 10" dia & +12 \\
\hline 2 & Type B ( ${ }^{6} \mathrm{LiF}$ converter/Two Surface-Barrier CPDs) & $10^{\prime \prime}$ dia & -60 \\
\hline $3^{*}$ & Repaired Type C (10mm cube ${ }^{6} \mathrm{Lil}(\mathrm{Eu}) / \mathrm{S} 1723$ Silicon Photodiode) & $10^{\prime \prime} \mathrm{dia}$ & +12 \\
\hline 4 & S1723 Silicon Photodiode ( $\mathrm{m}$ iluor) & $10 "$ dia & +12 \\
\hline 5 & 1"dia $\times 0.5^{\prime \prime}{ }^{6} \mathrm{LiI}(\mathrm{Eu}) / \mathrm{R3} 30-2$ Vacuum Photodiode & $10^{\prime \prime} \mathrm{dja}$ & +12 \\
\hline 6 & $0.5^{\prime \prime}$ dia. $\times 0.5^{\mathrm{n}}$ 6Lil(Eu)/R330-2 Vacuum Photodiode & $10 "$ dia & +12 \\
\hline 7 & $0.5^{\prime \prime}$ dia $\times 0.5^{\prime 6}{ }^{6} \mathrm{Li}(\mathrm{Eu}) / \mathrm{R} 330-2$ Vacuun Photodiode & 10" dia & +12 \\
\hline 8 & 1"dia $\times 1 "$ BC408, $2.5 \mathrm{~g} / 1^{6} \mathrm{LiF} / \mathrm{R} 847$ Vacuum Photodiode & $10^{*} \mathrm{dja}$ & +12 \\
\hline 9 & 1"dia $\times 0.5^{n} 6_{\mathrm{LiI}}(\mathrm{Eu}) / \mathrm{R} 330-2$ Vacuum Photodiode & $11^{\prime \prime} \mathrm{dia}$ & +12 \\
\hline 10 & 1"dia $\times 1 "$ BC430, unloaded/\$1723 Silicon Photodiode & none & +12 \\
\hline 11 & $0.5^{m}$ dia $\times 0.5^{\prime \prime}$ BC430, unloaded/S1723 Silicon Photodiode & none & +12 \\
\hline 12 & ORNL “PHIL TUBE" Residual Gamma Ray Detector & none & n.a. \\
\hline
\end{tabular}

Table 11. Calibration results $(c p m /(m r e m / h))$

\begin{tabular}{lcc|cc} 
& \multicolumn{2}{c|}{24 July 1985} & \multicolumn{2}{c}{31 July 1985} \\
Detector & Gamma rays & Neutrons & Gamma rays & Neutrons \\
& & & & \\
\hline 1 & $2.2 \pm 0.5$ & $13.6 \pm 0.7$ & $2.4 \pm 0.0$ & $12.0 \pm 0.7$ \\
2 & $30.8 \pm 1.3$ & $20.0 \pm 0.4$ & $30.8 \pm 0.5$ & $16.4 \pm 1.0$ \\
4 & $322.0 \pm 50$ & $1159 \pm 50$ & $434 \pm 15$ & $1186 \pm 51$ \\
3 & $92.1 \pm 3.1$ & $1021 \pm 44$ & $93.8 \pm 5.6$ & $9 ! 1 \pm 39$ \\
6 & $61.8 \pm 4.7$ & $519 \pm 23$ & $57.6 \pm 3.7$ & $466 \pm 21$ \\
\hline
\end{tabular}




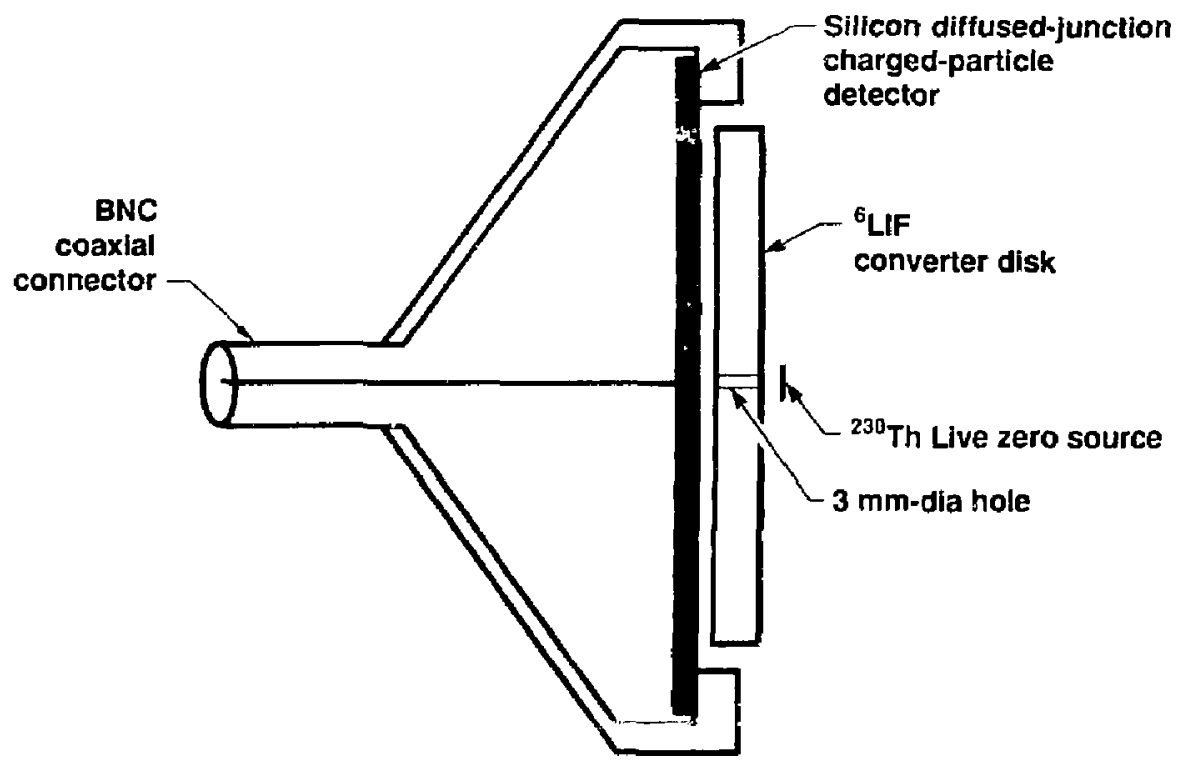

Figure 1. Type A detector diagram.

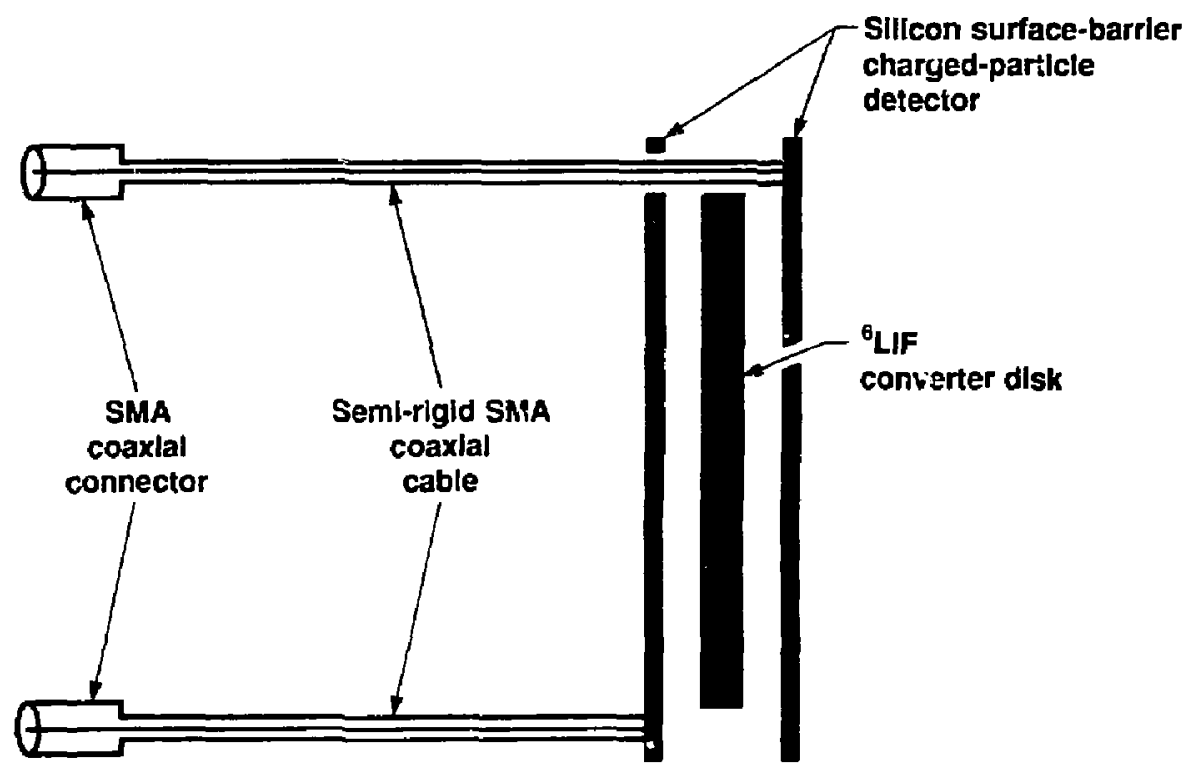

Figure 2. Type B detector diagram. 


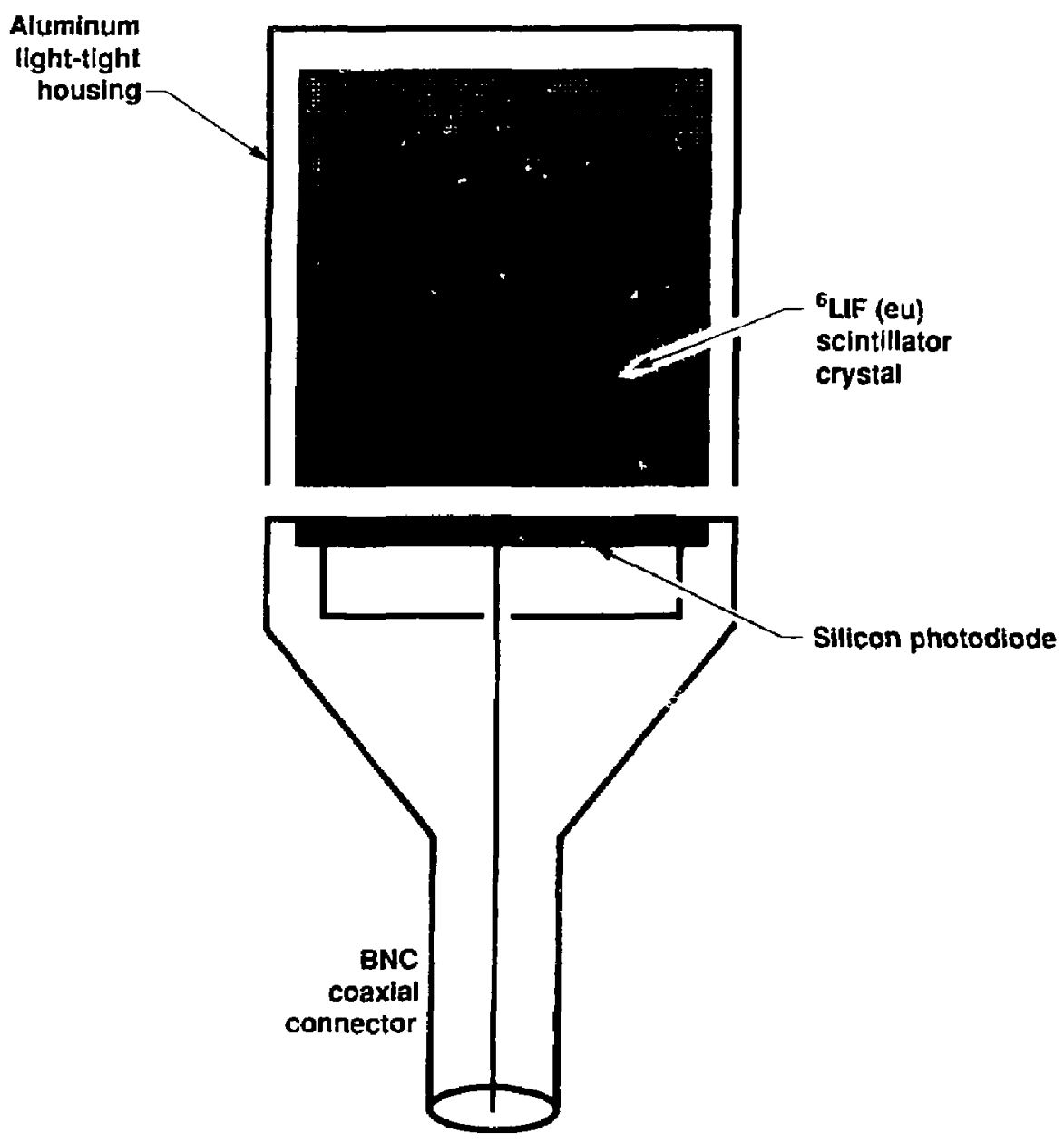

Figure 3. Type C detector diagram. 


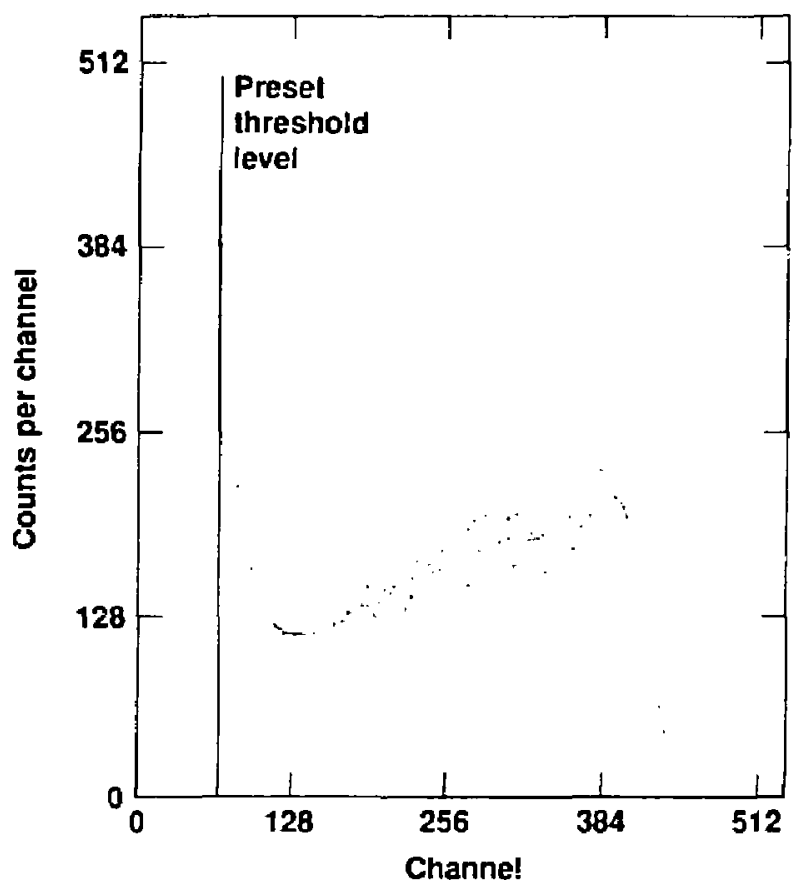

Figure 4. Type A detector pulse-height spectrum (10-in. diameter polyethylene moderator, Pu-Be source at $0.3 \mathrm{~m}$ ). 


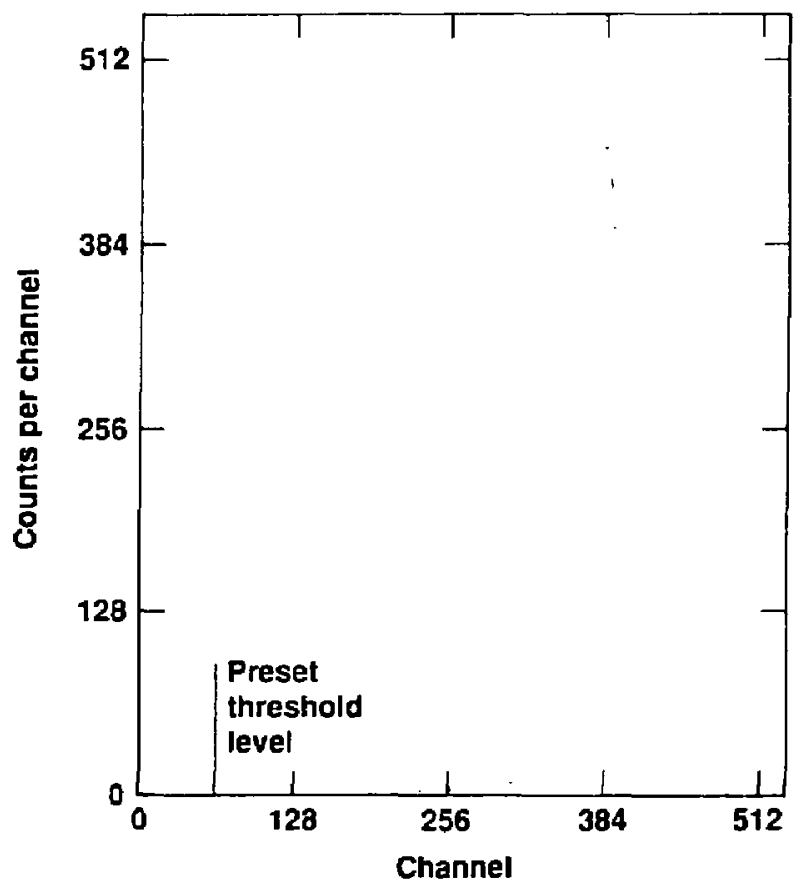

Figure 5. Type $\mathrm{C}$ detector pulse-height spectrum (10-in. diameter polyethylene moderator, $\mathrm{Pu}-\mathrm{Be}$ source at $0.3 \mathrm{~m}$ ). 


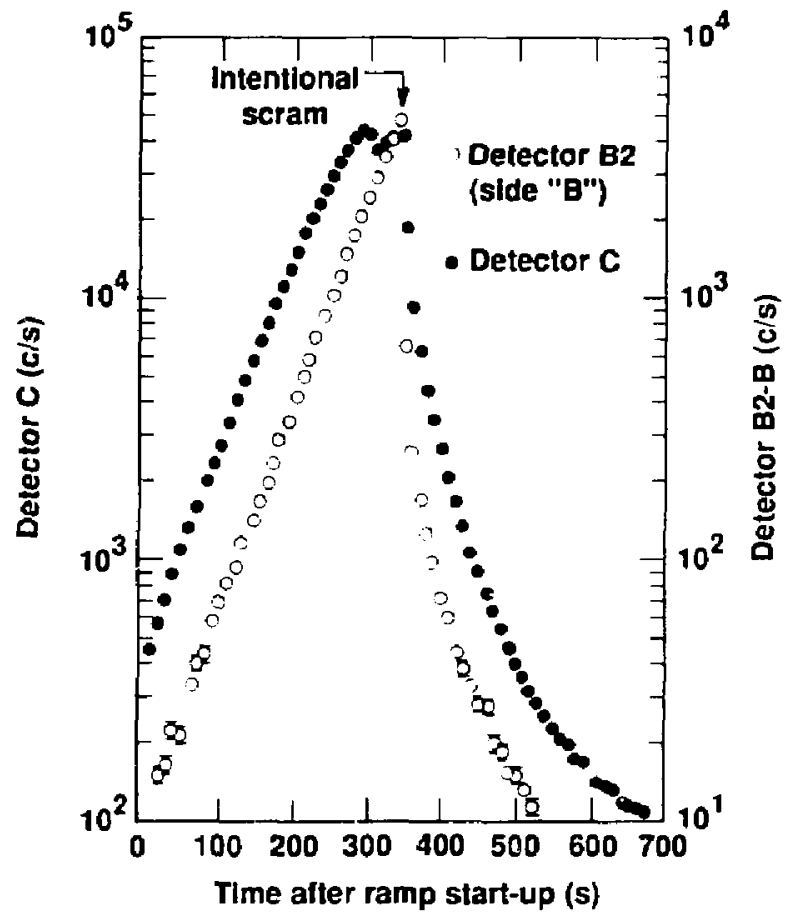

Figure 6. Comparison of Type B and Type C detectors for SHEBA 56-s ramp (run "8). 


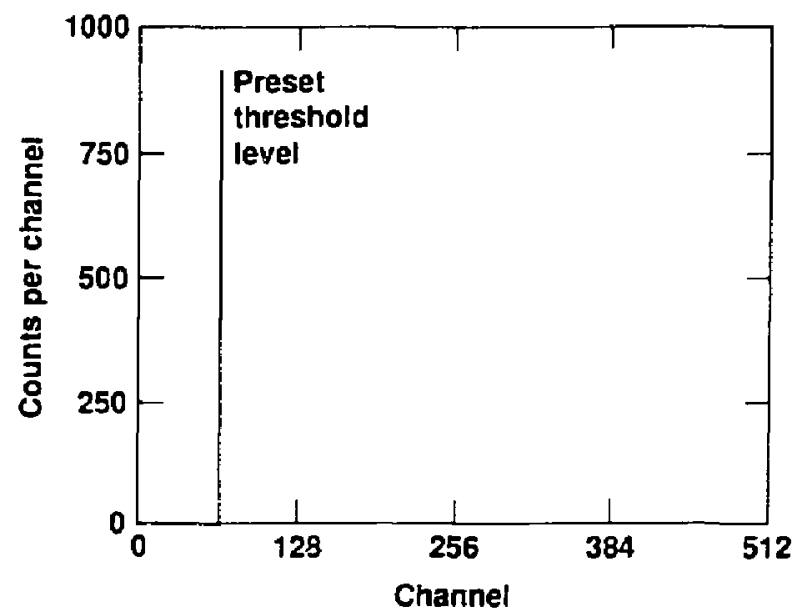

Figure 7. Typical Type A detector pulse-height distribution ( ${ }^{25 \Omega} \mathrm{Cf}$ source with $150 \mathrm{~mm} \mathrm{D}_{2} \mathrm{O}$ moderator at $1 \mathrm{~m})$. 


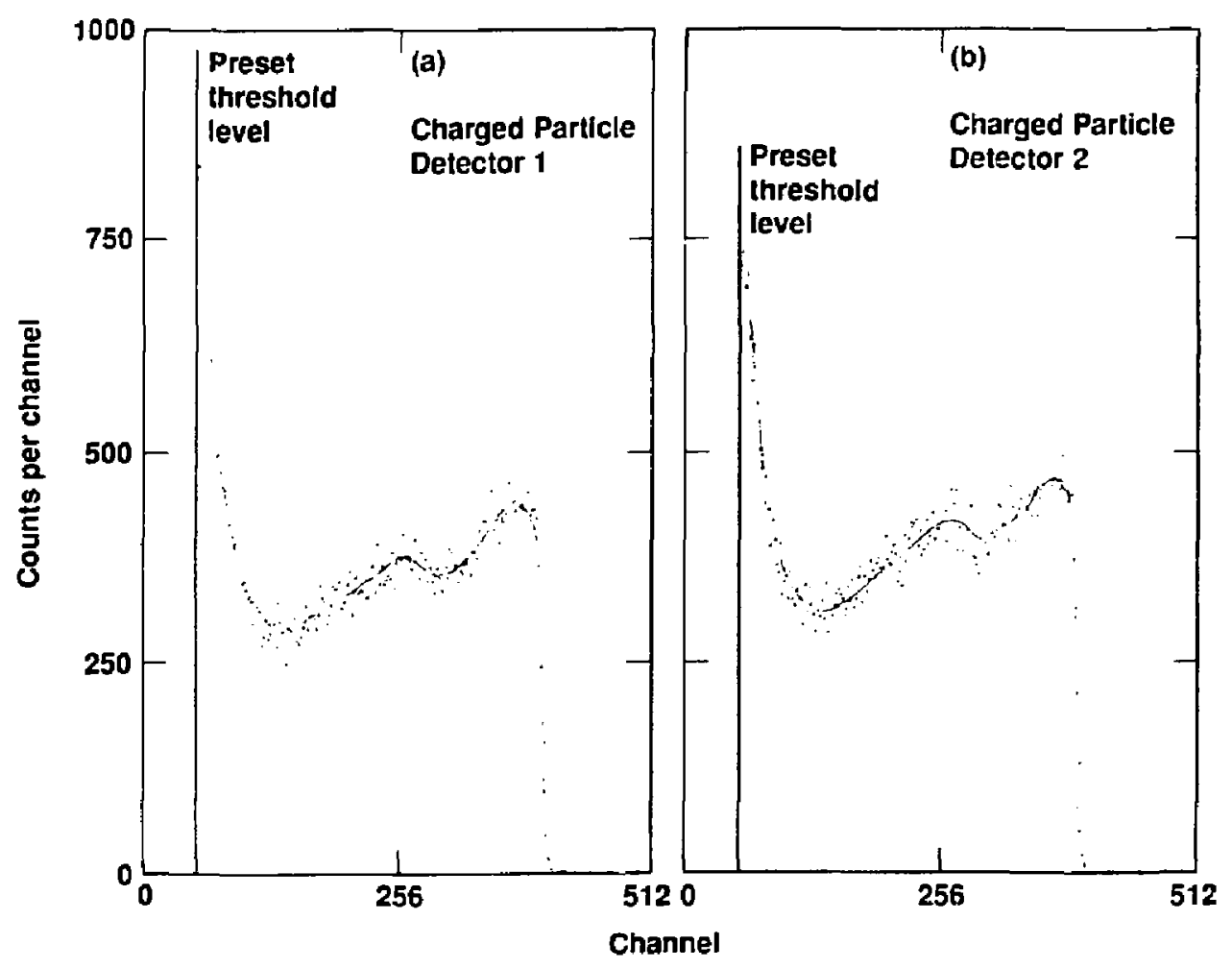

Figure 8. Typical Type B detector pulse-height distribution (Pu-Be source at $1 \mathrm{~m}$ ). 


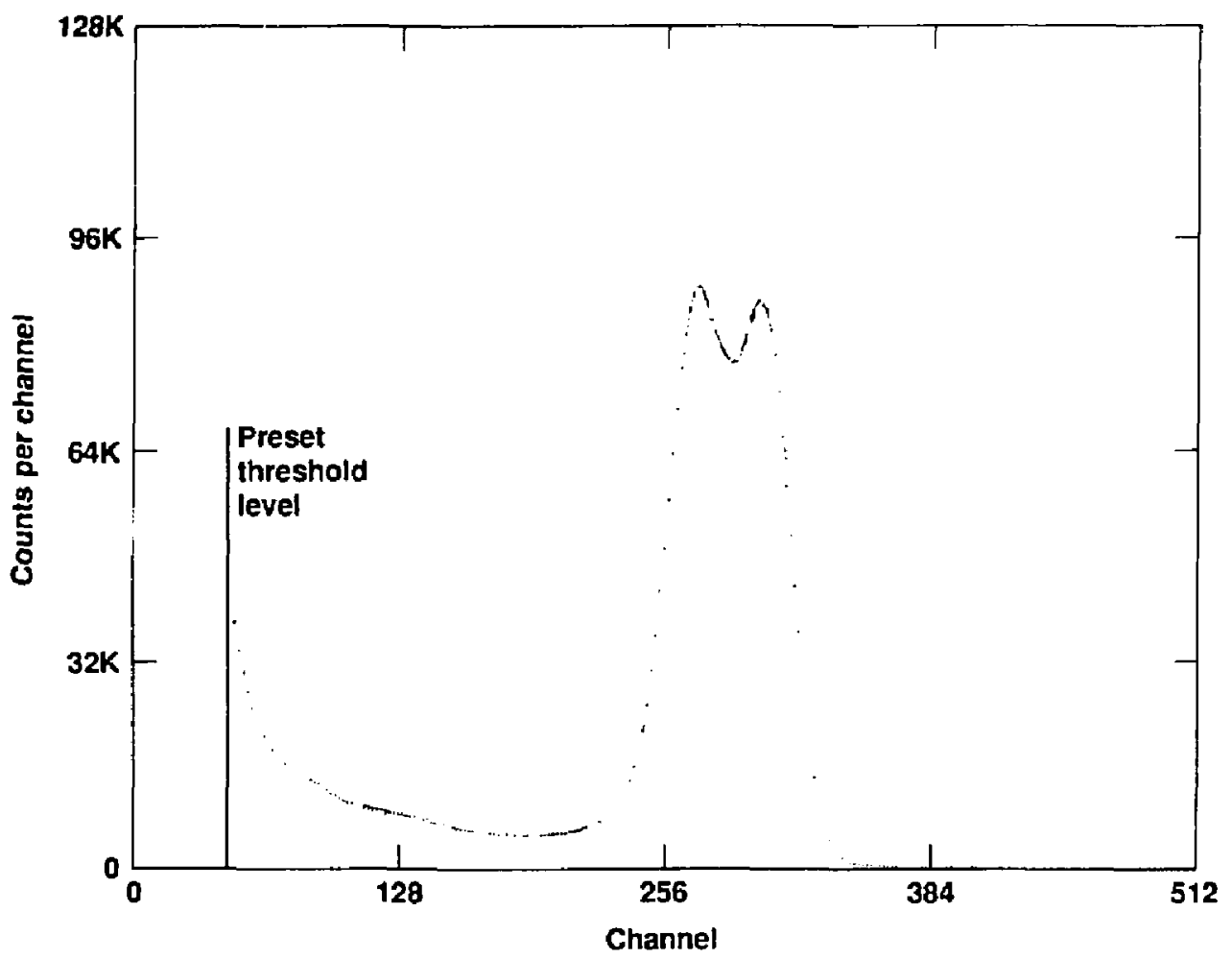

Figure 9. Type $\mathrm{C}$ detector pulse-height distribution after LANL tests $\left({ }^{252} \mathrm{C} f\right.$ source with $150-\mathrm{mm} \mathrm{D}_{2} \mathrm{O}$ moderator at $1 \mathrm{~m}$ ). 


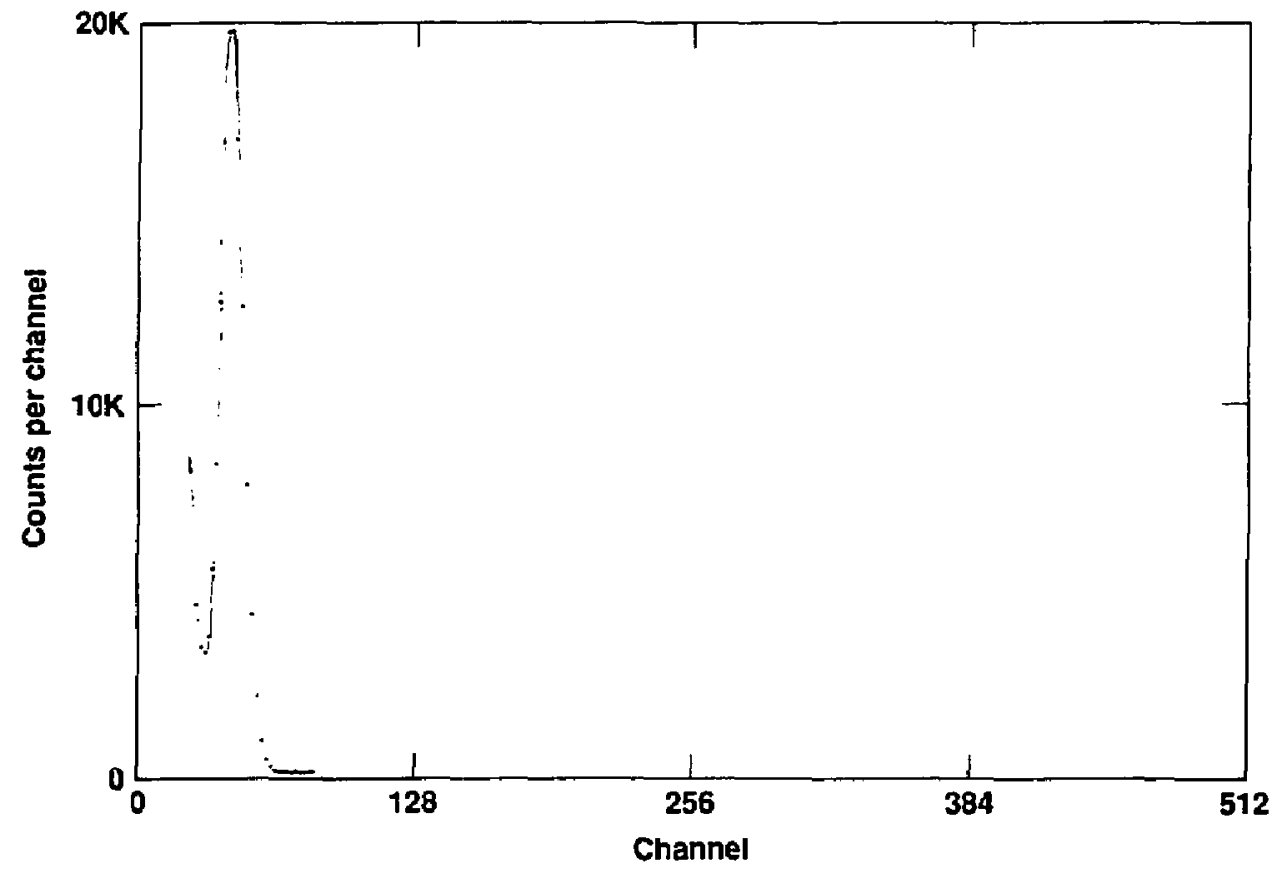

Figure 10. Pulse-height distribution: 1-in. diameter $\times 0.5$-in. ${ }^{6}$ Lil (Eu) fluor and vacuum photodiode in 10-in. polyethylene moderator, $\mathrm{Pu}-\mathrm{Li}$ neutron source. 


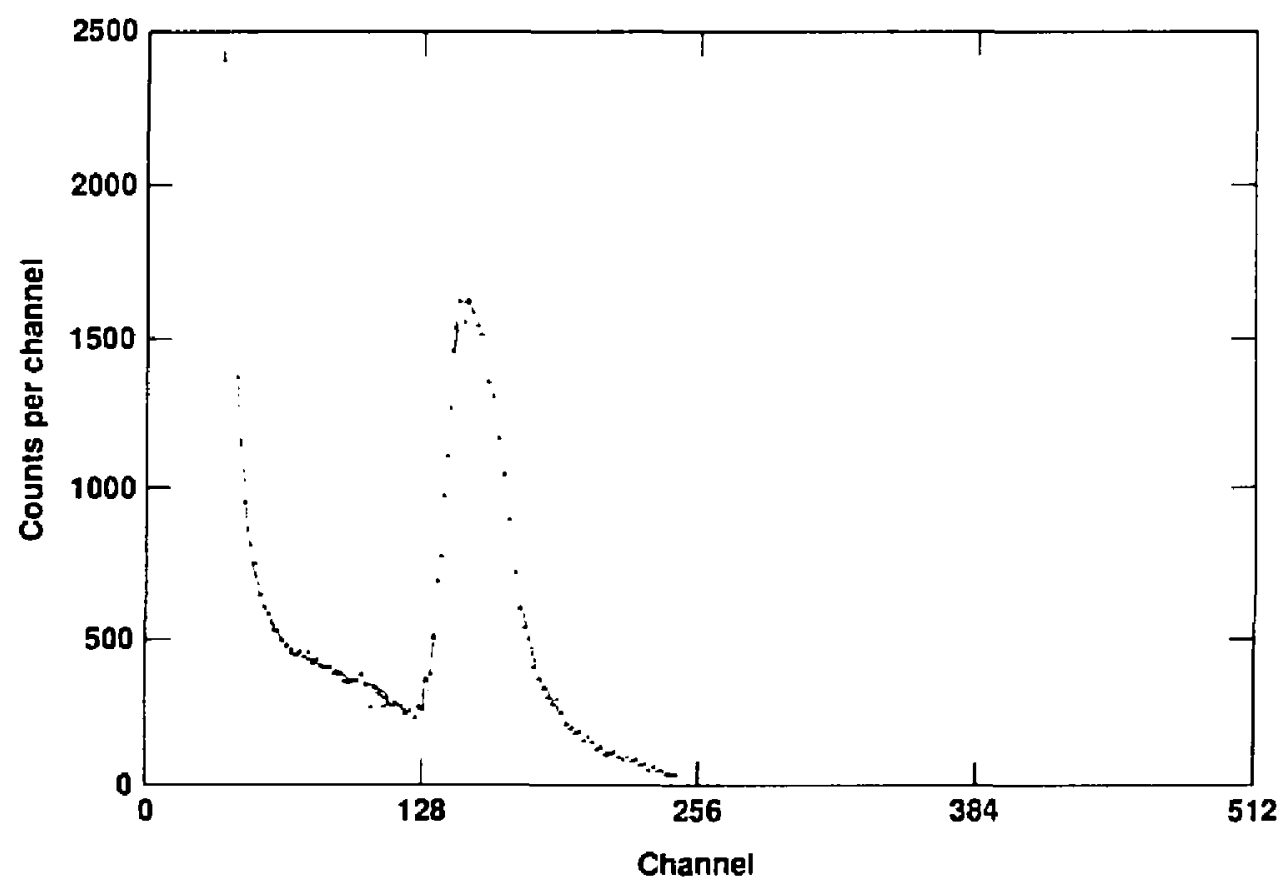

Figure 11. Pulse-height distribution: 1-in. diameter $\times 0.5$-in. ${ }^{6} \mathrm{LiI}(\mathrm{Eu})$ fluor and vacuum phototriode at $100 \mathrm{~V} / 100 \mathrm{~V}$ bias, moderated $\mathrm{P} u-B e$ neutron source. 


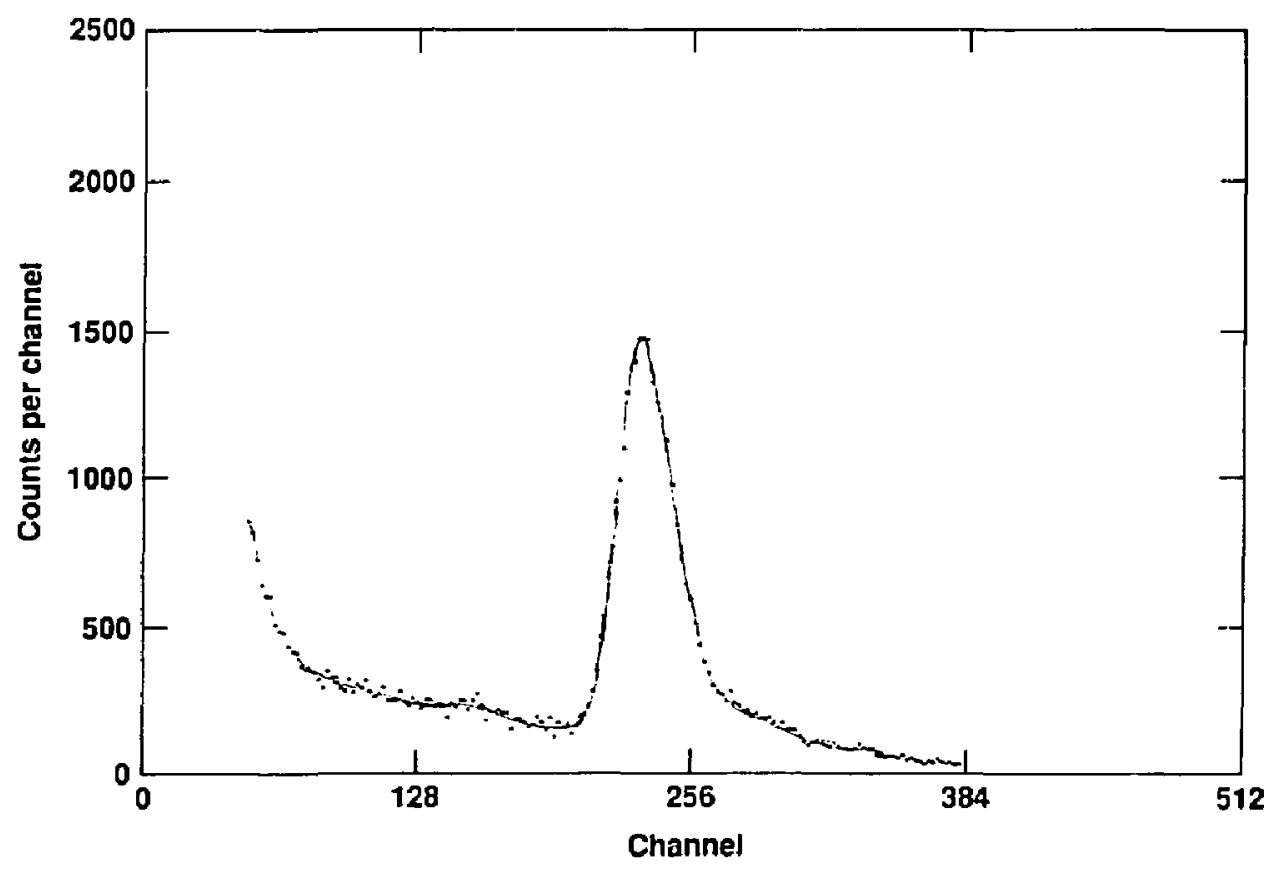

Figure 12. Pulse-height distribution: 1-in. diameter $\times 0.5^{6} \mathrm{Lil}$ (Eu) fluor and vacuum phototriode at $200 \mathrm{~V} / 200 \mathrm{~V}$ bias, moderated Pu-Be neutron source. 


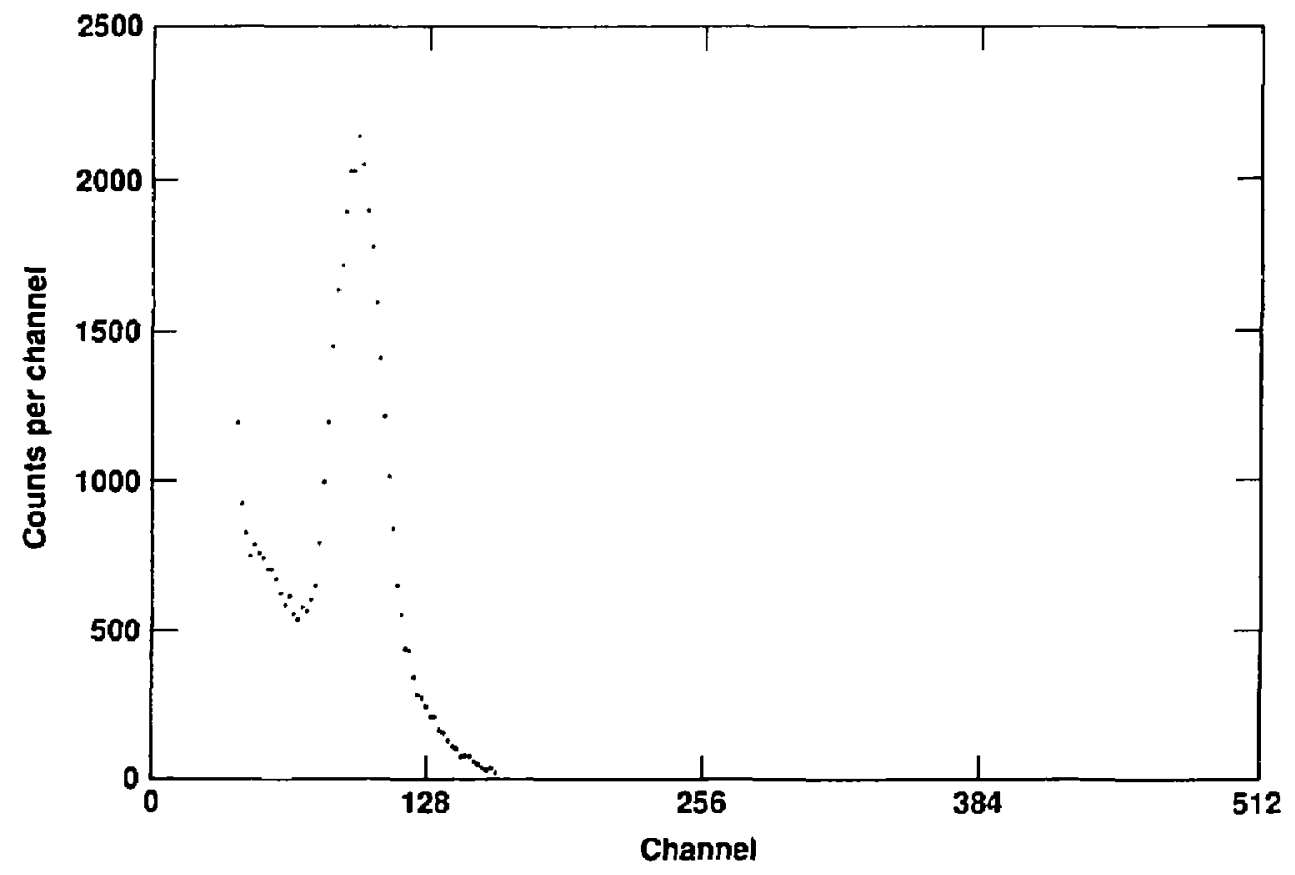

Figure 13. Pulse-height distribution: 1-ìn. diameter $\times 0.5^{6} \mathrm{LiI}(\mathrm{Eu})$ fluor and vacuum phototetrode at 50 V 150 V/50 V bias, moderated Pu-Be neutron source. 


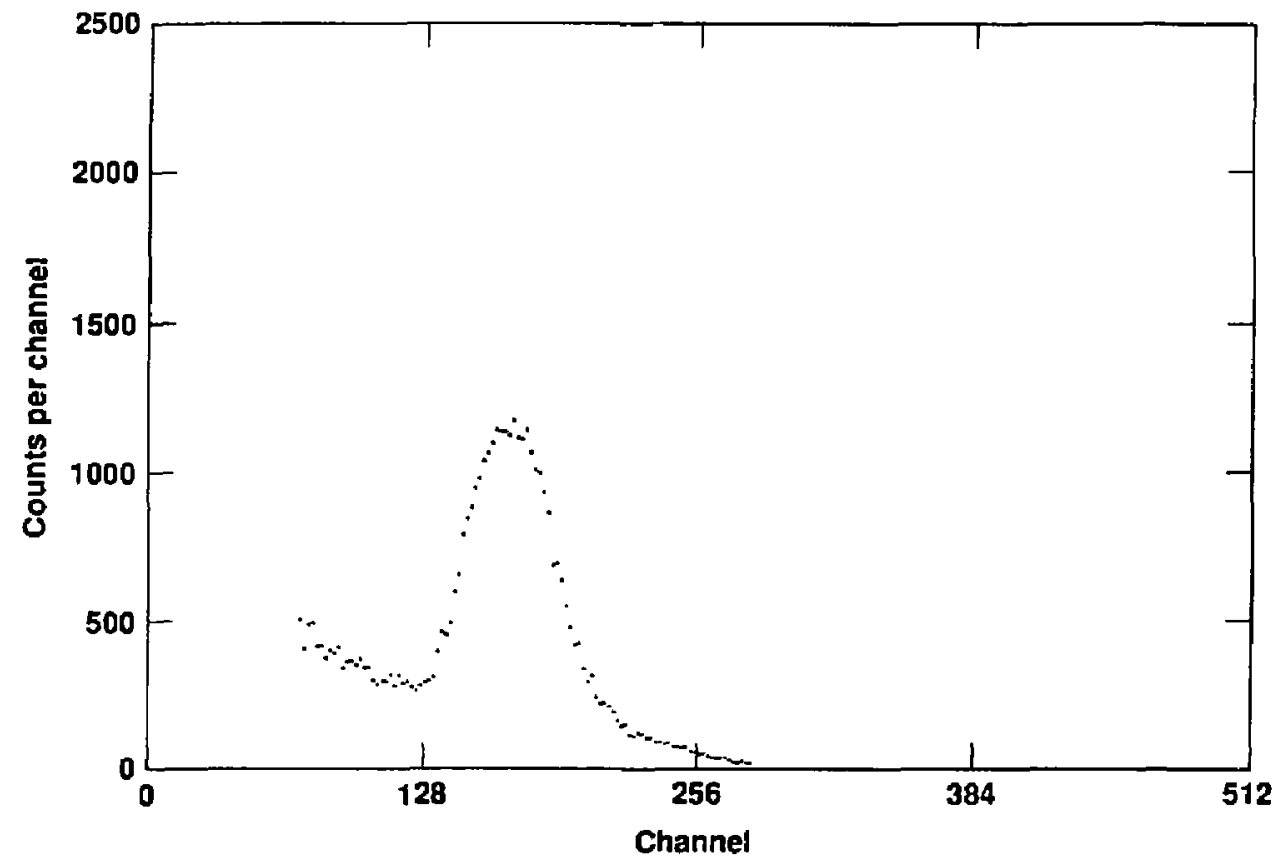

Figure 14. Pulse-height distribution: 1-in. diamter $\times 0.5^{6} \mathrm{LiI}$ (Eu) fluor and vacuum phototetrode at $100 \mathrm{~V} / 100 \mathrm{~V} / 100 \mathrm{~V}$ bias, moderated Pu-Be neutron source. 


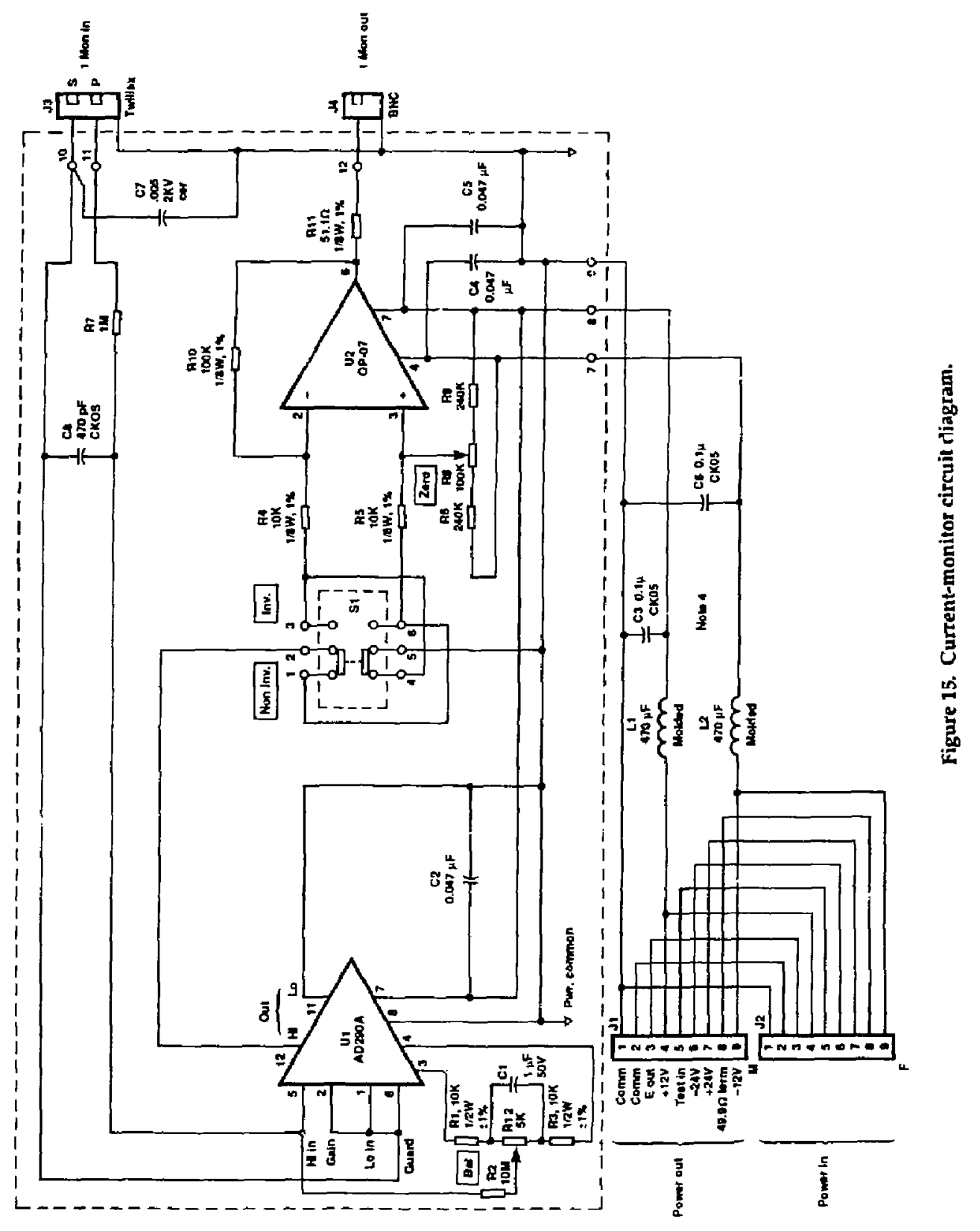




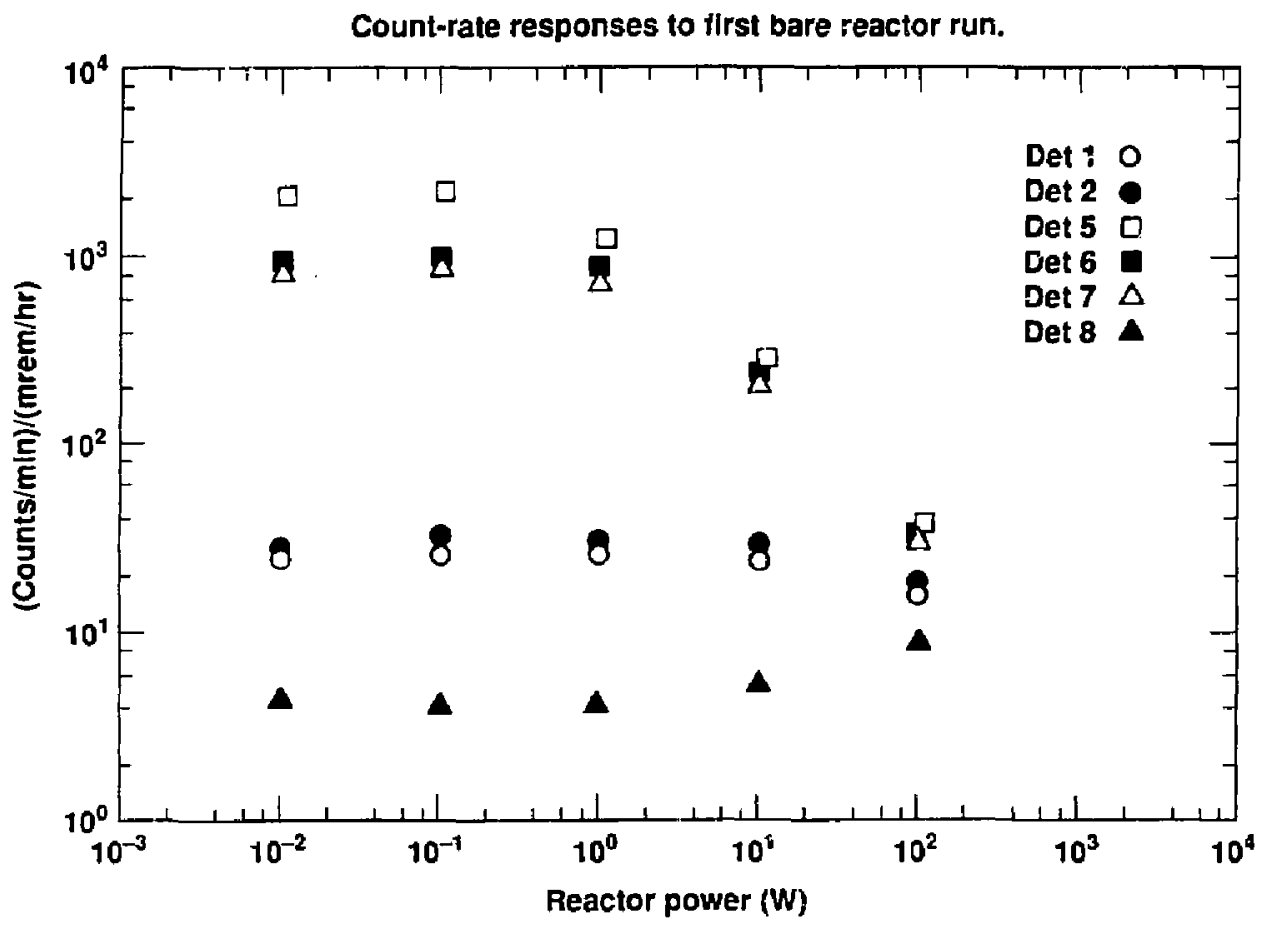

Figure 16. Response of detectors [(counts/min)/(mrem/h)] to bare HPRR-first steady-state runs. 
Count-rate responses to second bare reactor run.

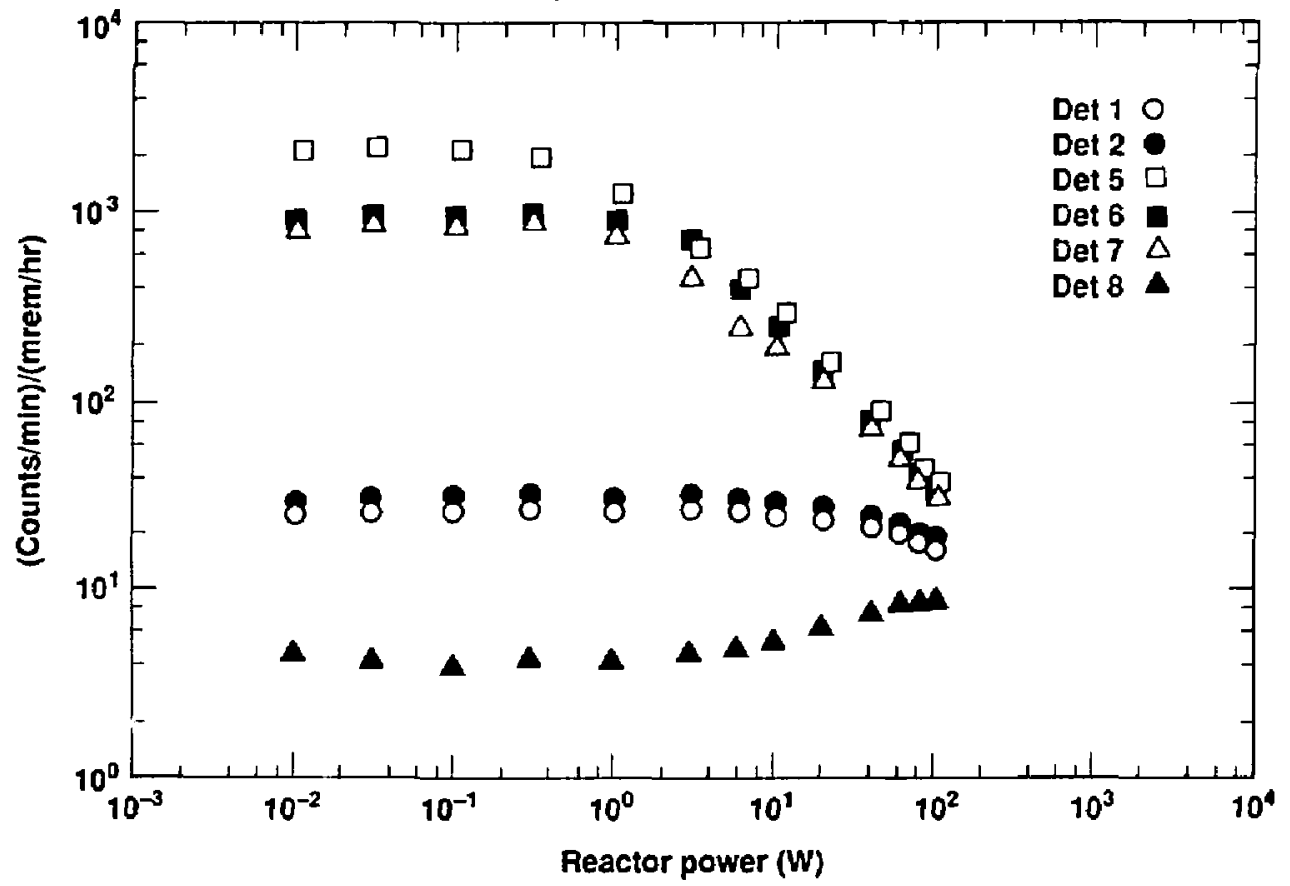

Figure 17. Response of detectors [(counts/min)/(mrem/h)] to bare HPRR一-second steady-state rurts. 


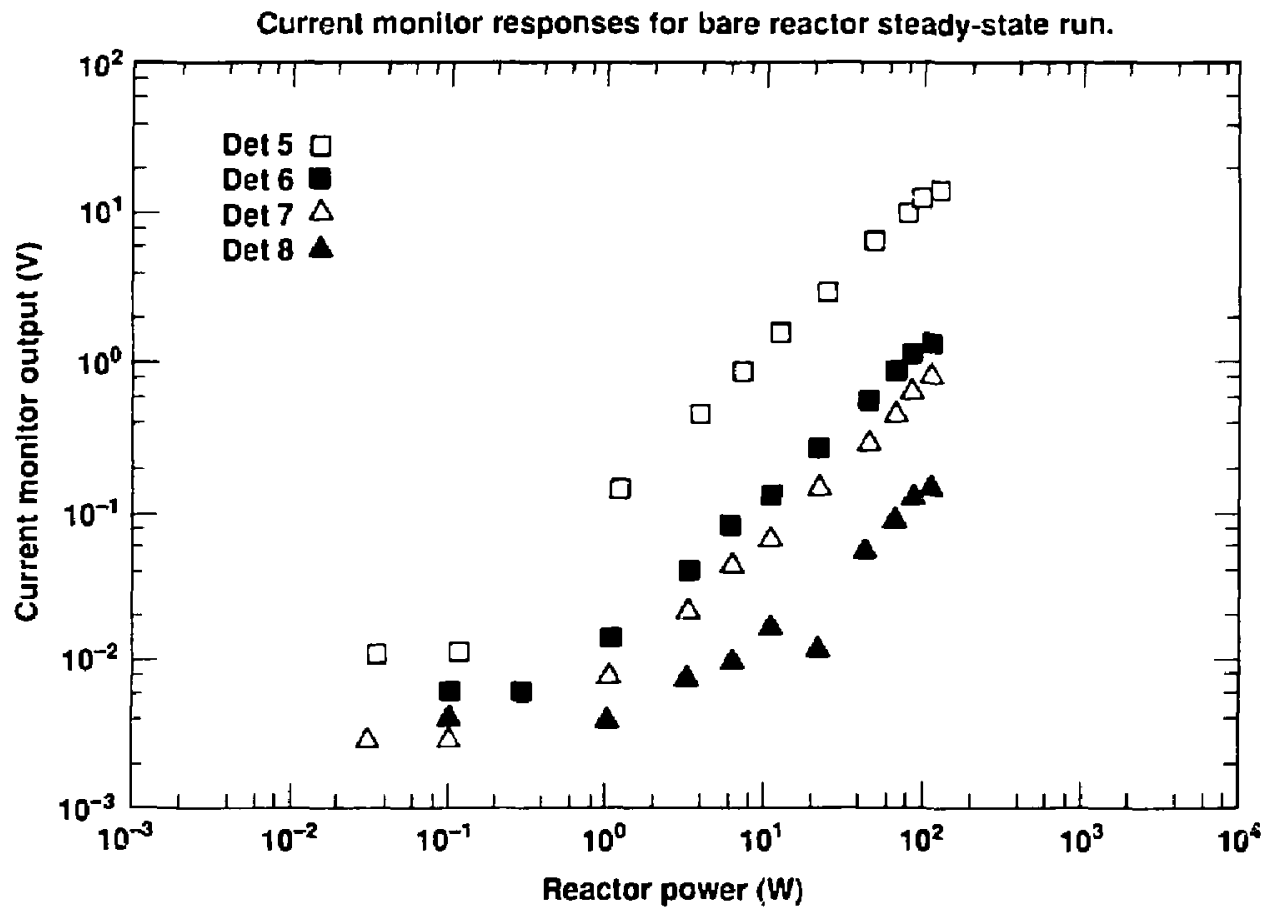

Figure 18. Current-monitor response of delectors to bare HPRR-second steady-state run. 


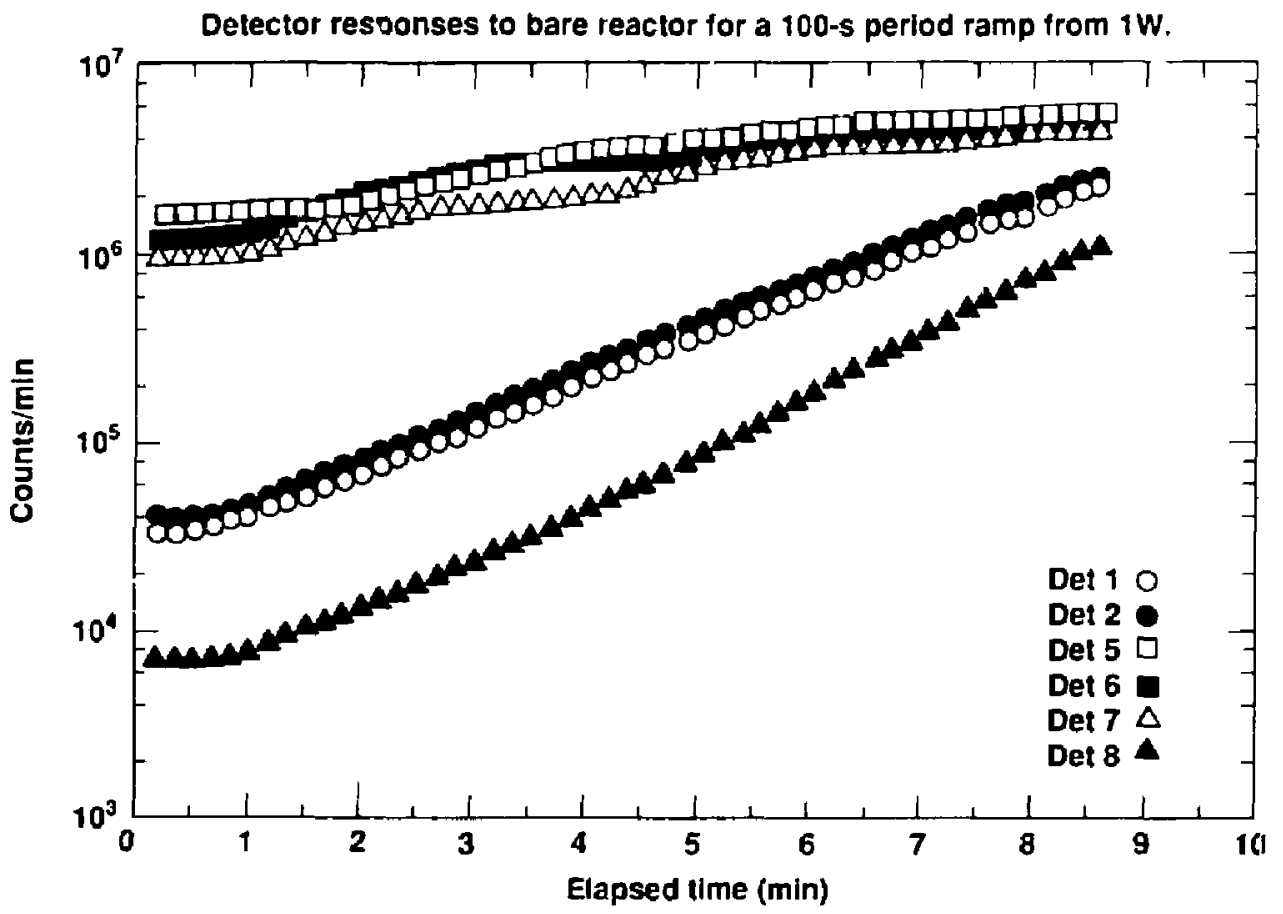

Figure 19. Count-rate response of detectors to bare HPRR-100-s period exponential ramp. 


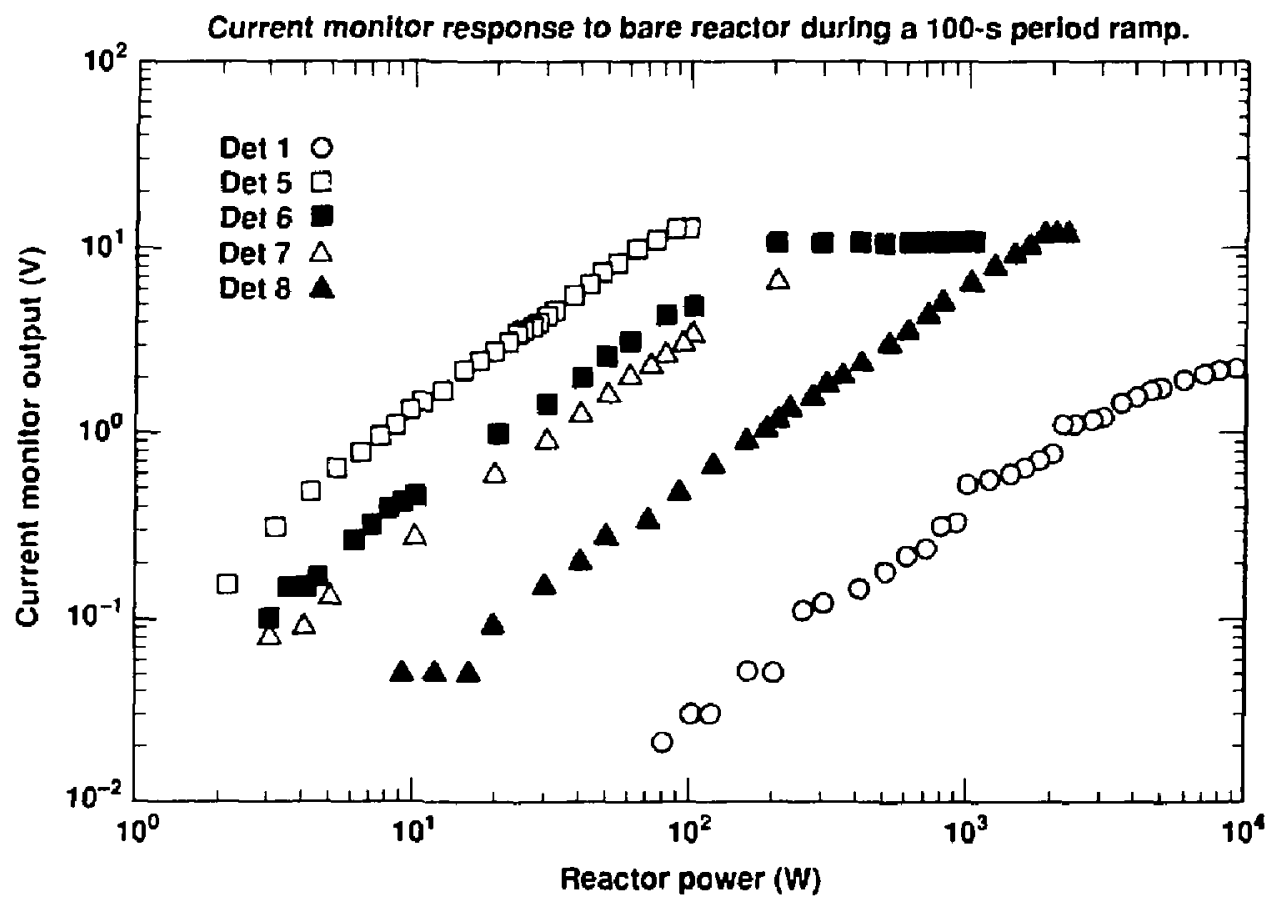

Figure 20. Current-monitor response of detectors to b e HPRR-100-s period exponential ramp. 
Count-rate responses to reactor shielded with lucite.

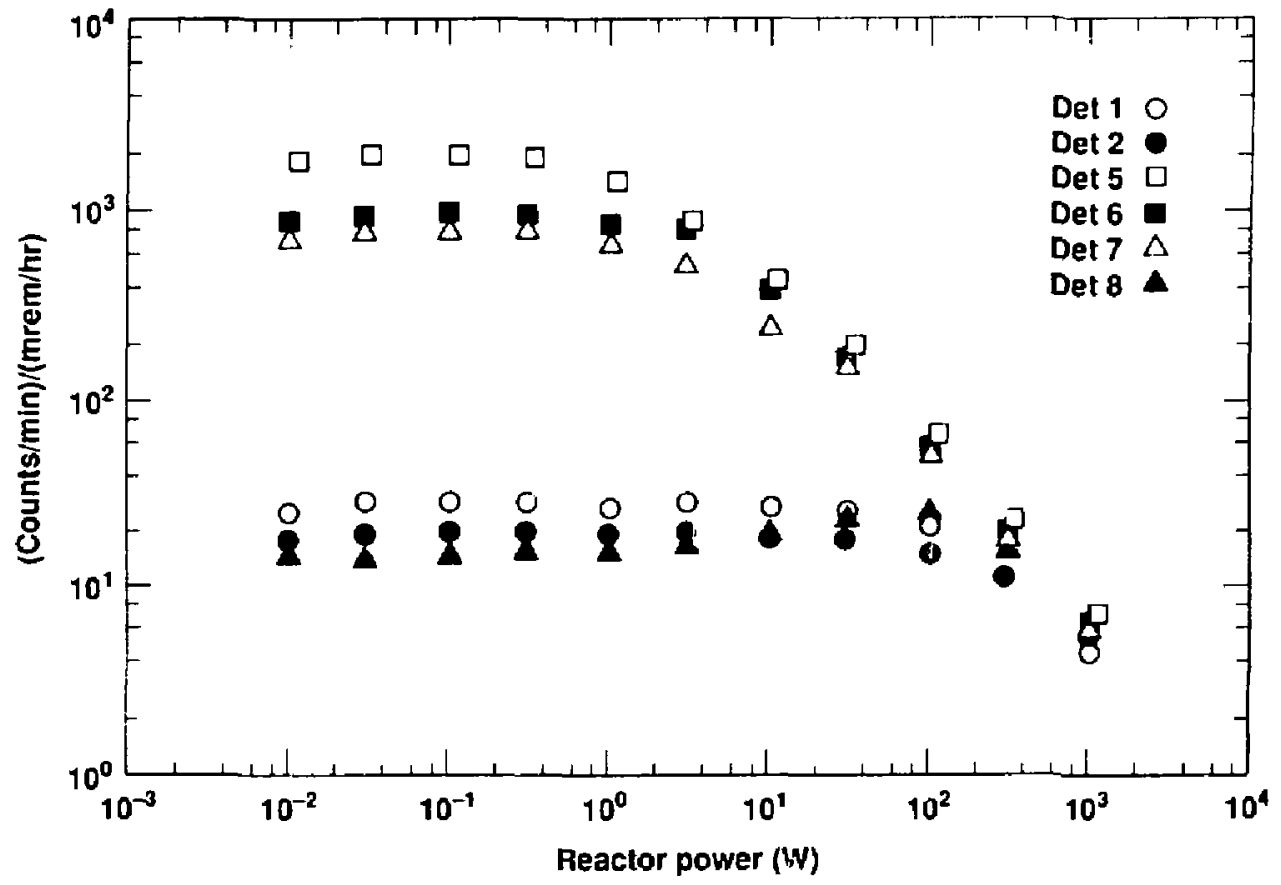

Figure 21. Response of detectors [(counts/min)/(mrem/h)] to HPRR behind lucite shieldsteady-state runs. 


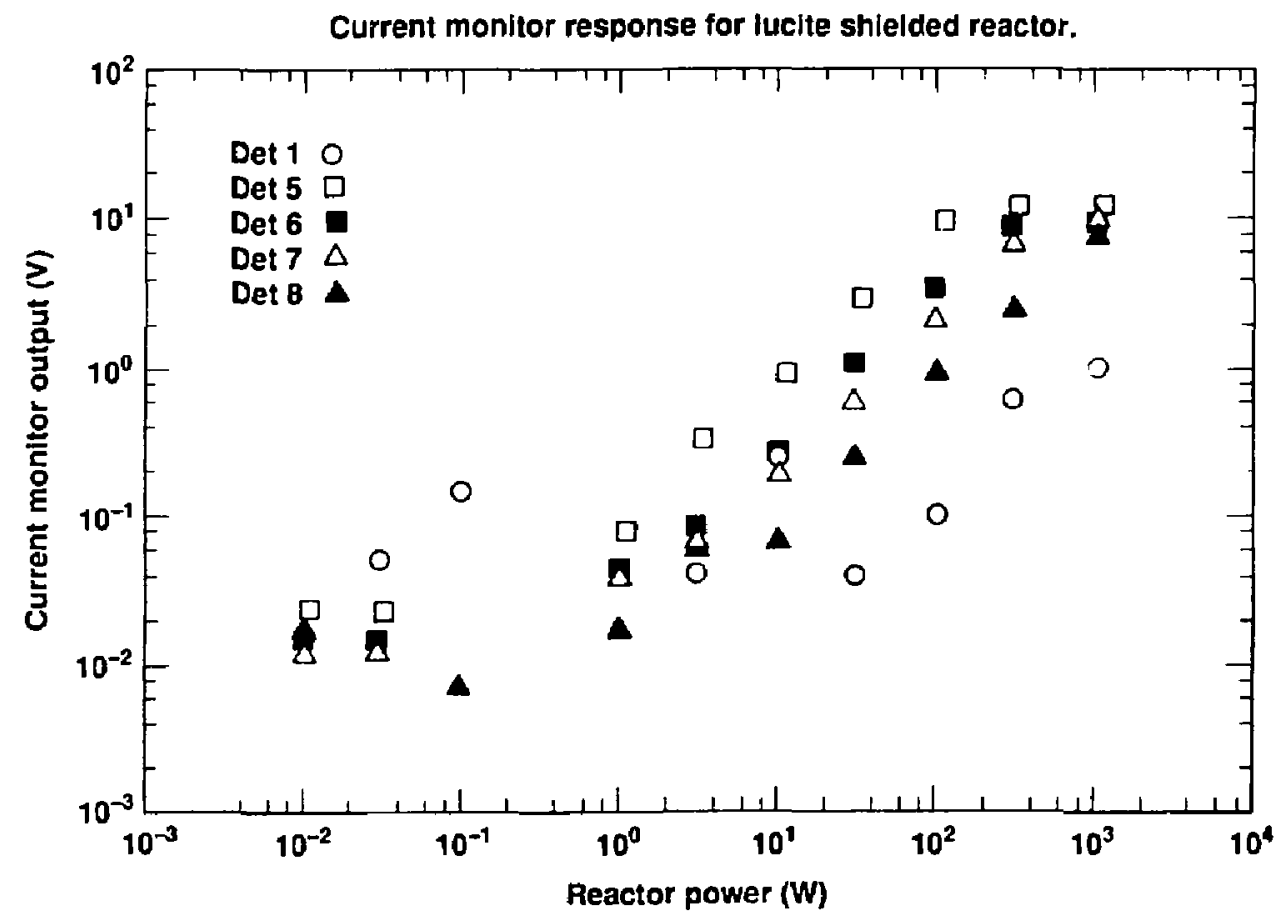

Figure 22 Current-monitor response of detectors to HPRR behind lucite shieldsteady-state runs. 


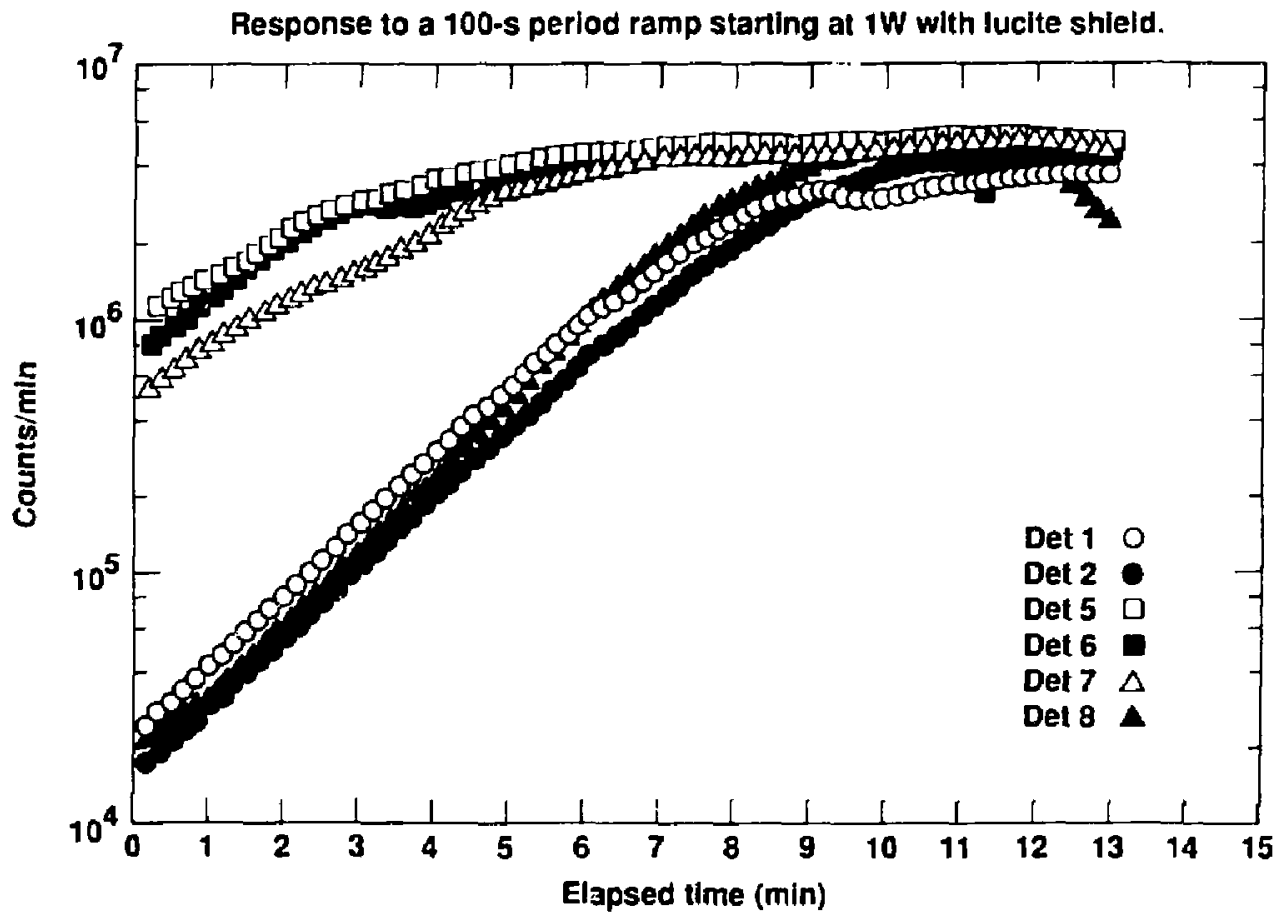

Figure 23. Count-rate response of detectors to HPRR behind lucite shield100-s period exponential ramp. 


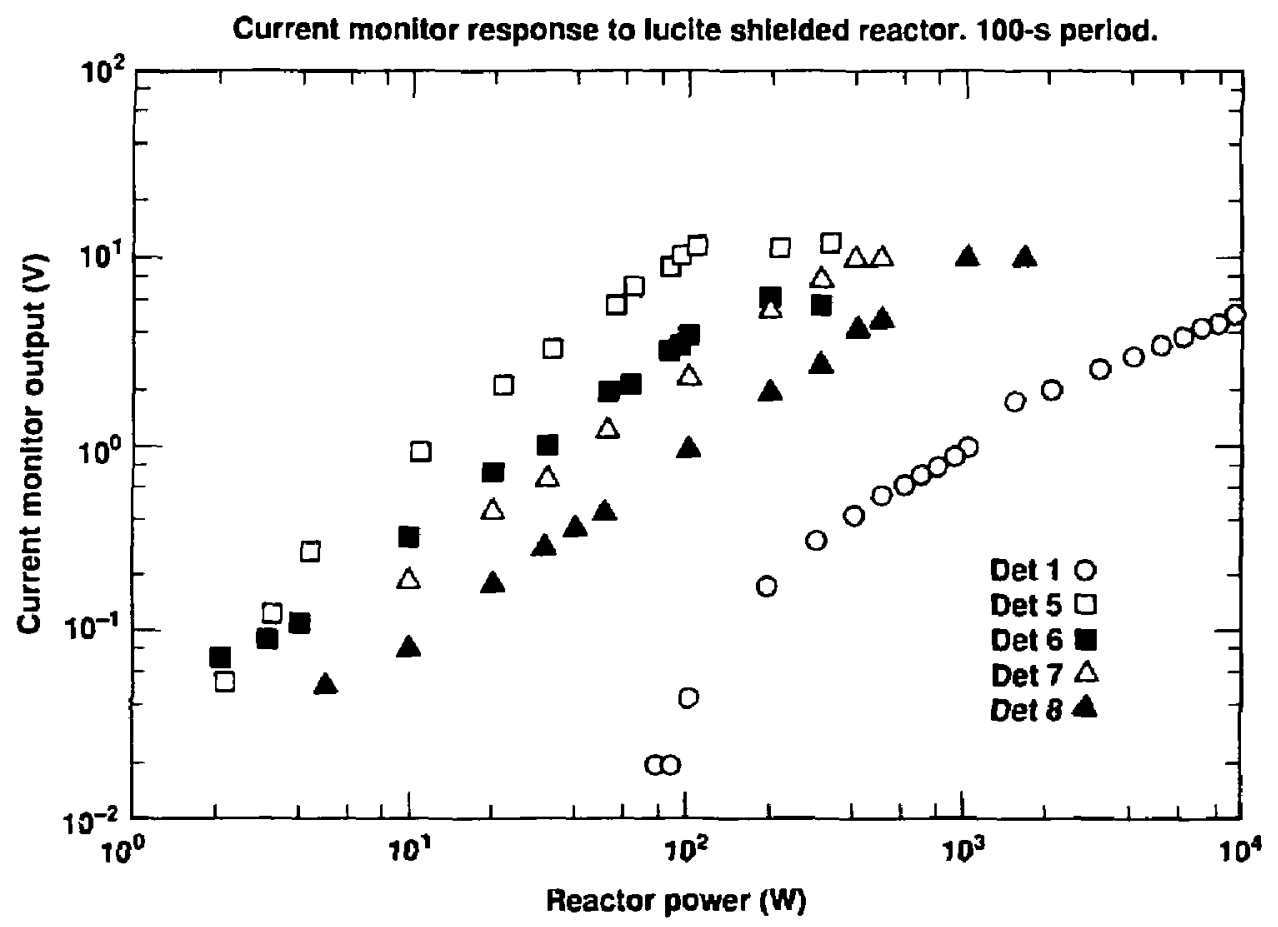

Figure 24. Current-monitor response of detectors to HPRR behind lucite shield100-s period exponential ramp. 